\title{
How Does Performing Demanding Activities Influence Prospective Memory? A Systematic Review
}

\author{
Patricia Matos', Diana R. Pereira', Pedro B. Albuquerque', and Flávia H. Santos² \\ 'School of Psychology, University of Minho, Braga, Portugal \\ ${ }^{2}$ School of Psychology, University College Dublin, Dublin, Ireland
}

\section{KEYWORDS}

prospective memory

ongoing task load

omission errors

commission errors
ABSTRACT

This paper is the first systematic review on the role of ongoing task load in prospective remembering, which was conducted according to the Preferred Reporting Items for Systematic Reviews and Meta-Analysis (PRISMA). Forty articles published between 1995 and 2020 were included. They evaluated prospective memory (PM) performance (i.e., the ability to remember to execute a delayed intention) in adult samples aged between 19 and 50 years old when the PM cue appeared under cognitively demanding conditions. The results revealed that people are more likely to fail to remember to perform a delayed intention at the appropriate circumstances or time in the future when their cognitive resources are taxed by demanding ongoing activities. We conclude the review by highlighting that the degree of working memory and executive resources seems to account for some of the discrepant findings and by proposing directions for future research.

\section{INTRODUCTION}

A common real-life demand is remembering to perform a specific task after some delay, termed prospective memory (PM; Einstein \& McDaniel, 1990; Loftus, 1971). Prospective memories are often formed and executed during other ongoing activities. Therefore, one must frequently be able to manage PM requirements alongside the demands of those background tasks - which can be difficult if the ongoing task (OT) processing is cognitively demanding, for instance, taking intermittent medicines while preparing a challenging meeting presentation while also attending a dental appointment in the middle of the afternoon. In such cases, the vital role of PM is most vividly evident when we experience some lapses, such as forgetting to take those medicines at the appropriate times.

Prospective remembering is effortful by recruiting cognitive resources that enable a complex balance between executing an intention and maintaining simultaneous ongoing tasks (Einstein \& McDaniel, 1996; Ellis, 1996; Kliegel et al., 2002). More specifically, apart from episodic memory, attentional and executive processes are required to recognize the appropriate contextual signals (e.g., seeing the medication box) without an explicit prompt to recall or act upon the intention. These processes are also required to manage PM processes within the context of concurrent activities that may offer distractions (Einstein \& McDaniel, 1996; Ellis, 1996; Kliegel et al., 2002). Moreover, executive functions such as inhibitory and task-switching abilities are essential to disengage from the OT and to interrupt it when the PM cue is detected or at the proper time (e.g., McDaniel et al., 1998; Schnitzspahn et al., 2013; Scullin et al., 2010). In this sense, PM intentions may be recalled by the association to a specific event that acts as a cue (i.e., event-based PM, EBPM, tasks; e.g. "I have to take the first shot with the breakfast"); or actively retrieved from memory at a specific time (i.e., time-based PM, TBPM, tasks; e.g., "I have to take my allergy medicines at 4:30 p.m."). An extensive body of literature has investigated how do people

Corresponding author: Patrícia Fernanda Ferreira Matos, School of Psychology, University of Minho, Campus de Gualtar, 4710-057 Braga, Portugal. E-mail: patri.norte@gmail.com 
successfully initiate EBPM and TBPM retrieval at the appropriate moment (e.g., Anderson \& McDaniel, 2019; Einstein et al., 1998; McDaniel \& Einstein, 2000; Shelton \& Scullin, 2017; Smith, 2003; Smith \& Bayen, 2005). Time-based PM tasks place greater demands on self-initiated processes compared to EBPM tasks as they require active monitoring for the passage of time.

Theoretically, the preparatory attention and memory processes (PAM) theory holds that PM is dependent upon the engagement of strategic monitoring of the environment that supports the detection of associated cues (Smith, 2003; Smith \& Bayen, 2005). In this view, the realization of delayed intentions seems to always require the allocation of controlled executive resources. In turn, the multiprocess theory (MPT) suggests that an intention is spontaneously retrieved (Einstein \& McDaniel, 2005) when the PM cue is salient (e.g., stands out perceptually from the OT stimuli) or focal (i.e., the PM cue information may be easily decoded from the OT when there is a processing overlap between the PM and the OT). For example, while doing an account report at work we may need to actively search for some cues or review our intentions periodically in order to remember to take medicines. At other times, catching sight of the medicine box acts as an environmental cue that triggers retrieval to take them. Still, it should be noted that even if the context may support an automatic noticing of the PM cue, resources are likely to be mobilized to select and interpret the contextually cued retrieved intention (Anderson et al., 2019; Einstein \& McDaniel, 2010; McDaniel \& Einstein, 2000).

Overall, working memory (WM) and attentional executive resources are devoted to maintaining concurrent activities in an activated state, while evaluating whether the responses are appropriate for other intended tasks to properly retrieve and execute previous planned intentions (e.g., Basso et al., 2010; Cohen, 2017; Einstein et al., 1997; Engle, 2002; Kidder et al., 1997; Marsh \& Hicks, 1998). Within a limited capacity system in which different goals may compete for resources, a good deal of research has considered that PM retrieval might be influenced by differences in OT demands. Simply put, PM may be sensitive to the number of resources that are available when a cue is encountered. That is, when engrossed in a task, environmental cues that are related to previously established intentions are less likely to be noticed. For instance, we may not be able to monitor for the intention to take medicines or interrupt our ongoing activity to do so, because our cognitive resources are taxed by challenging annual accounts report that we are required to complete at work.

When studying PM in laboratory settings, participants are commonly required to press a designated key whenever they see a target cue or after a specific period of time had elapsed while they are engaged in other ongoing activity (Einstein \& McDaniel, 1990). To simulate highly demanding settings, the primary OT is made more challenging by increasing its difficulty (e.g., an $n$-back task with two levels of difficulty) or by introducing a secondary OT (e.g., signal the occurrence of two odd digits while performing a lexical decision task, LDT; e.g., Kidder et al., 1997; Marsh \& Hicks, 1998; McDaniel \& Scullin, 2010). In this review, we assume that OT difficulty can be determined by the amount of cognitive resources required to perform it. The more the ongoing activities recruit cognitive resources, the fewer resources are available to perform the PM task (Marsh \& Hicks, 1998; Kidder et al., 1997).

Although it has been shown that individuals might be less likely to successfully remember to perform a PM task if they are busily engaged in demanding situations (e.g., Einstein et al., 1997, Experiment 1; Harrison et al., 2014, Experiments 2 and 3), some contradictory results have been reported (e.g., Harrison et al., 2014; Marsh \& Hicks, 1998; Smith \& Hunt, 2014). Importantly, examining the available literature hints at the idea that the mixed findings can be framed as differences in the amount of WM and executive resources that people must allocate to the OT and PM processing (Baddeley, 1996; Cohen, 2017; Engle, 2002). In other words, changing the difficulty of the OT via manipulation of short-term memory load without changing the executive control demands might be insufficient for affecting young adults' PM performance (Marsh \& Hicks, 1998). In line with this, studies that manipulated the retrieval context by asking participants to decide whether the colour of the words matches any of the colours shown on previous trials, or by asking them to monitor a string of background digits for the consecutive presentation of odd numbers showed that PM performance was not particularly disturbed in these conditions (e.g., Horn et al., 2011; Smith \& Hunt, 2014; Smith et al., 2012).

Contrary to this, switching between task sets limits processing resources that are available for strategic monitoring, thereby reducing the likelihood of realizing a delayed intention (Marsh et al., 2002; McNerney \& West, 2007). Likewise, in random generation tasks, people are required to monitor their output for stereotypic sequences and plan changes in their strategy (Baddeley, 1986; Harrison et al., 2014, Experiment 2 and 3; McDaniel et al., 2008, Experiment 2). These findings indicate that higher levels of OT task-switching, monitoring, or planning requirements may impose more cognitive control demands and, thus, PM may suffer due to overload. However, it should be noted that depending on other factors, such as PM cue salience or focality, PM performance may be enhanced despite OT difficulty (Trawle et al., 2014). In line with the MPT, salient cues are likely to capture attention and prompt further processing, and, as a consequence, PM-related responses may be executed without much effort.

Thus far, it is not yet clear which load conditions are more prone to influence PM performance. Therefore, the present systematic review aimed to (a) examine the prevalence of PM failures omission errors under demanding OT contexts; and to (b) synthesize the extent to which EBPM and TBPM tasks are affected by highly demanding ongoing activities. By having these two goals in mind, we intended to identify possible factors that could account for the discrepant findings already described in the literature (e.g., characteristics of the OT or the type of cognitive load manipulation, type of PM task, focality and salience of the PM cue) and, ultimately, to characterize which cognitive load conditions are more susceptible to the occurrence of these memory failures. In line with this proposal, we were particularly interested in OT load manipulations which are known to influence the availability of cognitive resources at the time of PM retrieval (see Meier \& Zimmermann, 2015, for supporting evidence of different types of 
load). Given the methodological heterogeneity across studies, we opted to systematically organize the selected articles as a function of the PM tasks (i.e., EBPM and TBPM) and OT manipulation (i.e., increasing OT difficulty, adding a secondary OT, and task-switching procedures).

\section{METHOD}

\section{Search Strategy}

This systematic review follows the guidelines of Preferred Reporting Items for Systematic Reviews and Meta-Analyses (PRISMA, Moher et al., 2015). First, Scopus, PubMed, and Web of Science databases were searched, from the earliest available date to the end of April 2018, for the following descriptive verbal expressions: "prospective memory", "prospective remembering", "delayed intentions", combined with "OT demand ${ }^{\star ”, ~ " d i v i d e d ~ a t t e n t i o n ", ~ " c o g n i t i v e ~ l o a d ", ~ " w o r k i n g ~ m e m o r y ~}$ load", "background activit*", "load manipulation", and "secondary demand*". The search was then updated to include articles published from 2018 until January 2020. Additionally, we hand-searched reference lists on the articles identified through the prior database search and relevant articles. This strategy was also used to include articles with task-switching paradigms since it has been demonstrated that switching between tasks involves more costs, and thus more cognitive load, than repeating the same task across time (Monsell, 2003). The first two authors worked independently, selected the articles at each stage of the review (identification, screening, and inclusion) by using Cochrane's online software for systematic reviews, Covidence ${ }^{\infty}$. The authors resolved disagreements through discussion until a consensus was reached.

\section{Eligibility Criteria}

Included studies were required to meet the following criteria: (a) had experiments involving young and middle-age adults, (b) used EBPM or TBPM tasks, (c) tested PM performance as a dependent variable, (d) manipulated the cognitive load during the OT (i.e., by increasing OT difficulty, adding a secondary task or using a task-switching procedure), (e) embedded the PM cues in the OT, to ensure that resources were shared between those tasks, and (f) were published in a peerreviewed, English language journal. Hence, records in other languages, commentaries, narrative/qualitative reviews, editorials, book chapters, and abstracts were not considered for further analysis. The following exclusion criteria were also applied: (a) studies that manipulated the cognitive load of the PM cue (e.g., Ballhausen et al., 2017; Cohen, 2013), as these conditions have been shown to affect OT performance (Meier \& Zimmermann, 2015), (b) studies that included delay-execute conditions or activity-based PM tasks (i.e., the PM response had to be performed after a particular task has finished; Brewer et al., 2011), as PM cues did not appear during the OT, (c) studies that included clinical samples, as PM might be particularly affected in this context (e.g., Albinski et al., 2012), (d) studies that involved drug interventions and/or ingestion of substances (e.g., Rusted \& Trawley, 2006), or that manipulated other factors including sleep (e.g., Barner et al., 2016), or that used neuromodulation techniques such as transcranial magnetic stimulation (e.g., Basso et al., 2010), (e) experiments that included children, adolescents, and older adults (e.g., Cheie et al., 2017; Zollig et al., 2007) given that previous research had demonstrated that PM follows an inverted U-shape developmental trajectory (Zuber \& Kliegel, 2019; Zimmermann \& Meier, 2006). So, by including only young and middle-age adults, age effects were somewhat restricted to this developmental stage.

\section{Selection of Studies}

Figure 1 displays the PRISMA flow diagram showing a total of 356 articles identified. We found 328 articles through the initial database search (i.e., 199 articles in Web of Science, 92 in Scopus, and 37 in PubMed) and 19 articles in an updated search since April 2018 to the end of January 2020 (i.e., 13 articles in Web of Science, four in Scopus, and two in PubMed). In addition, nine articles were identified through other sources (i.e., hand-searching reference lists). The articles were exported to Zotero ${ }^{\star}$ to eliminate duplicates $(n=72)$. Title and abstract screening led to the identification of 60 articles. The main reasons for exclusion at this stage were unrelated to PM or the inclusion of clinical samples, children or elderly participants. In the case of any doubt concerning the application of the inclusion or exclusion criteria, the manuscripts were included in the "full-text reading" phase. After the full texts were screened, 40 articles were found to meet the inclusion criteria, and 20 articles were excluded (see details in Figure 1). Of note, we did not conduct a meta-analysis because the articles differed methodologically in several ways (e.g., study design, OT, and PM tasks), which may lead to meaningless results according to Cochrane recommendation for systematic reviews (Higgins \& Green, 2011). Instead, results were organized and described following a systematic narrative approach

\section{Coding Procedure}

For each article included in the systematic review, the following details were extracted for each experiment: the author(s) and year of publication, the number and mean age of the sample; design (between-subjects, within-subjects), the OT used and the number of trials and blocks; the PM task; the cue type (e.g., word; image; letter), including whether the cue was specific or categorical (i.e., a specific word or a word from the animal category), the number of cues; cue focality (focal; non-focal), that is, the degree of overlap between the processing required by the PM cues and the $\mathrm{OT}^{1}$, cue saliency, that is, the distinctiveness of the cue in relation to the OT (e.g., PM cue stands out perceptually from the OT stimuli), data regarding the PM performance (accuracy) and OT performance (accuracy and response times - RTs), and key findings that summarize how the load manipulation influenced both PM and OT performance. The information was initially extracted by the first author and then thoroughly reviewed by the second author. Finally, it was organized by the type of PM task (EBPM and TBPM) and by the type of OT load manipulation (increasing the primary OT demands, adding a secondary OT, or task-switching procedures). 


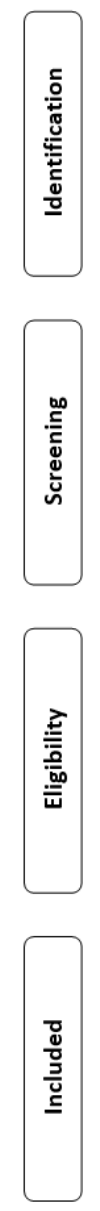

\section{RESULTS}

To date, 40 articles met our research criteria in examining the role of OT load on prospective remembering. The SCImago Journal and Country Rank was used as an indicator of visibility in scientific domains by ranking the journals in which articles were published. The articles were published in journals with different quartiles: 22 in Q1 journals, 16 in Q2 journals and two in Q3 journals. These quartiles also indicated that most articles were published in higher impact factor journals. The earliest work with a direct association with cognitive load and PM was published by Einstein et al. (1995). Moreover, 22\% of the records ( $n=8$ ) were published between 1995 and 2000, 46\% ( $n$ $=17)$ were published between 2001 and 2010, and 38\% $(n=15)$ were published between 2011 and 2020.

The 40 published articles, containing a total of 62 experiments, differed methodologically in several ways. Most of the experiments investigated EBPM tasks (56/62) rather than TBPM tasks (7/62). Since only three studies assessed the role of the OT load on PM commission errors, we decided to discuss these findings and suggest future work in the Discussion section. Thus, in the following sections, we describe the results (a) regarding EBPM tasks and TBPM tasks according to (b) the OT manipulation (i.e., increasing the primary OT demands, adding a secondary OT, or using a task-switching procedure). To shed some light on how increasing demands influence PM performance, we classified studies according to how the task demands were manipulated (i.e., WM tasks increasing storage or executive function demands, reasoning tasks, long-term memory, LTM, and other tasks). Lastly, we detail some other relevant features that seem to modulate the occurrence of PM omission failures.

\section{Event-Based Prospective Memory Tasks}

\section{INCREASING PRIMARY ONGOING TASK DEMANDS}

Some experiments directly manipulated the difficulty of the primary OT, that is, they increased the cognitive demands required to perform the ongoing activities in which the PM cues were embedded (see Table 1). In five experiments the OT load was manipulated by requiring WM storage demands, that is, using a colour-matching task in which participants had to decide whether the colour of a word matched any of the colours shown on previous trials. In such cases, no differences were found between groups with different levels of OT difficulty despite the fact that focal and specific PM tasks were used (i.e., pressing a keyboard key when target words appear; Horn et al., 2011; 


\begin{tabular}{|c|c|c|c|c|}
\hline \multirow{2}{*}{ Experiment } & \multirow{2}{*}{$\begin{array}{c}\text { Sample } N \\
(\text { age- } M ; S D)\end{array}$} & \multirow{2}{*}{ Ongoing task } & \multicolumn{2}{|c|}{ Key findings } \\
\hline & & & PM & OT \\
\hline \multicolumn{5}{|l|}{ WM storage } \\
\hline Horn et al., 2011-1 & $64(\mathrm{n} / \mathrm{a})$ & Color-matching task & $=$ & $\downarrow \%$ and RTs \\
\hline Horn et al., 2011-2a & $27(\mathrm{n} / \mathrm{a})$ & Color-matching task & $=$ & $\downarrow \%$ \\
\hline Horn et al., 2011-2b & $29(\mathrm{n} / \mathrm{a})$ & Color-matching task & $=$ & $\downarrow \%$ \\
\hline Smith et al., 2012 & $29(\mathrm{n} / \mathrm{a})$ & Color-matching task & $=$ & $\downarrow \%$ \\
\hline Smith \& Hunt, 2014 & $100(19.3 ; .12)$ & Color-matching task & $=$ & $\downarrow \%$ \\
\hline Otani et al., 1997-1 & $60(\mathrm{n} / \mathrm{a})$ & $\begin{array}{l}\text { HL: six words repetition; LL: three words repetition; NL: articulatory } \\
\text { suppression task }\end{array}$ & $=$ & $\downarrow \%$ \\
\hline Otani et al., 1997-2 & $60(\mathrm{n} / \mathrm{a})$ & $\begin{array}{l}\text { HL: six words repetition; LL: three words repetition; NL: articulatory } \\
\text { suppression task ( } 15 \text { s per trial) }\end{array}$ & $=$ & $\downarrow \%$ \\
\hline Kidder et al., 1997 & $90(19.6 ; 2.1)$ & Recall words at unpredictable intervals & $\downarrow$ & $\downarrow \%$ \\
\hline \multicolumn{5}{|l|}{ WM executive processing } \\
\hline Fronda et al., 2020 & $21(29 ; 8)$ & Mental arithmetic task & $=$ & $\downarrow \%$ \\
\hline Lewis-Peacock et al, 2016 & $25(23.2 ; \mathrm{n} / \mathrm{a})$ & $N$-back test and lexical decision task & 1 & $\downarrow \%$ \\
\hline West et al., 2006 & $18(\mathrm{n} / \mathrm{a})$ & $N$-back test (letters) & $=$ & $\downarrow \%$ and RTs \\
\hline West \& Bowry, 2005 & $18(19.78 ; .81)$ & $N$-back test (letters) & $\downarrow$ & $\downarrow \%$ and RTs \\
\hline Barutchu et al., 2019 & $28(25.04 ; 4.25)$ & $N$-back test (letters) & $=$ & t FA \\
\hline Möschl et al., 2019 & $80(21.79 ; 3.16)$ & $N$-back test (letters) & 1 & $\mathrm{n} / \mathrm{a}$ \\
\hline Marsh \& Hicks, 1998-1 & $54(\mathrm{n} / \mathrm{a})$ & Star counting task & $\downarrow$ & $\downarrow \%$ \\
\hline \multicolumn{5}{|l|}{ Other tasks } \\
\hline Lee \& McDaniel, 2013 & $112(\mathrm{n} / \mathrm{a})$ & Anagram task & $=$ & $\downarrow \%$ and RTs \\
\hline Rendell et al., 2007-2 & $60(20.1 ; \mathrm{n} / \mathrm{a})$ & $\begin{array}{l}\text { Face-naming task }(\mathrm{HL}=\text { recall the names of famous faces }+ \text { write words } \\
\text { beginning with a specific letter; } \mathrm{LL}=\text { estimate the age of faces }+ \text { write comments) }\end{array}$ & $=$ & $=$ \\
\hline Gonneaud et al., 2011 & $\begin{array}{l}\text { YA: } 29(24.3 ; 4.5) \\
\text { MA: } 20(51 ; 7)\end{array}$ & Mental addition task & $=$ & $\mathrm{n} / \mathrm{a}$ \\
\hline Stone et al., 2001-1a & $28(\mathrm{n} / \mathrm{a})$ & Planning aircraft routes through a circuit of waypoints & 1 & $\downarrow \%$ \\
\hline Stone et al., 2001-1b & $28(\mathrm{n} / \mathrm{a})$ & Planning aircraft routes through a circuit of waypoints & $\downarrow$ & $\downarrow \%$ \\
\hline
\end{tabular}

Note . WM = Working memory; $\mathrm{PM}=$ Prospective memory; $\mathrm{OT}=$ Ongoing task; $\mathrm{HL}=$ High load; $\mathrm{LL}=$ Low load; $\mathrm{NL}=$ No load; $\mathrm{YA}=$ Younger adults; MA = Middle-age adults; FA = False alarms; $\downarrow$ = Worse performance; $=$ Similar performance; $\mathrm{n} / \mathrm{a}=$ not available.

Smith et al., 2012; Smith \& Hunt, 2014). The same pattern was revealed by Otani and et al. (1997) that used a task with three levels of storage demand, that is, participants were asked to perform an articulatory suppression task and repeat three or six previously presented words. Conversely, even though Kidder et al. (1997) did not observe a decrement in identifying PM cues by increased WM storage (i.e., asking participants to recall words at unpredictable intervals), the qualitative processing required to identify the cue (i.e., press a key whenever a background pattern appears) differed from that required to perform the OT. Also, some other studies did not find a PM impairment when an LTM task (Rendell et al., 2007, Experiment 2) or a semantic processing task (Lee \& McDaniel, 2013) were used.

By contrast, increasing the OT requirement of WM and attentional executive resources had a deleterious effect on the ability to execute a delayed intention. Lewis-Peacock et al. (2016), and West and Bowry (2005) used an $n$-back task. The former instructed participants to judge if the lexical status of a current probe matched one of the probes presented one or two trials before (1-back and 2-back, respectively). In the latter, participants judged whether a letter was repeated 1- or 3-items back in a list. The same impairment pattern of results was found recently by Möschl et al. (2019). It is worth noting that West et al. (2006) also asked participants to perform a demanding n-back task. Nonetheless, PM retrieval may have been promoted by the salient and focal PM cue used in their study (i.e., pressing the "V" key when target letters appear while performing an n-back letters task), ensuring successful PM. Moreover, Marsh and Hicks (1998, Experiment 1) asked participants to count stars forward and backward to increment or decrement a running total, respectively. As this task required inhibiting one cognitive process in order to activate another, the authors found a PM impairment. Likewise, performing demanding planning tasks during the retention interval seems to limit the resources that can be devoted to the PM task (which, in the current case, also required planning skills) and, henceforth, participants fail to successfully perform the planned intention (Stone et al., 2001).

\section{ADDING A SECONDARY ONGOING TASK}

Some studies added a secondary OT in order to mimic complex daily situations (see Table 2). First, in line with previous findings, signalling the appearance of three consecutive tones of the same pitch (tone-monitoring WM task) or the occurrence of two/three consecu- 
TABLE 2.

Experiments on the Effect of Cognitive Load in Event-Based Prospective Memory Omission Errors, by Adding a Secondary Ongoing Task

\begin{tabular}{|c|c|c|c|c|c|}
\hline \multirow{2}{*}{ Experiment } & \multirow{2}{*}{$\begin{array}{c}\text { Sample } N \\
\text { (age-M;SD) }\end{array}$} & \multirow{2}{*}{ Secondary ongoing task } & \multirow{2}{*}{ Ongoing task } & \multicolumn{2}{|c|}{ Key findings } \\
\hline & & & & PM & OT \\
\hline \multicolumn{6}{|l|}{ WM storage } \\
\hline Harrison et al., 2014-1 & $56(\mathrm{n} / \mathrm{a})$ & Digit-monitoring task & Lexical decision task & $=$ & $\downarrow \%$ and RTs \\
\hline McDaniel et al., 1998-3 & $30(\mathrm{n} / \mathrm{a})$ & Digit-monitoring task & Pleasantness rating task & 1 & $\downarrow$ RTs \\
\hline McGann et al., 2002-1 & $48(\mathrm{n} / \mathrm{a})$ & Digit-monitoring task & Sentence validity task & 1 & $=$ \\
\hline McGann et al., 2002-2 & $48(\mathrm{n} / \mathrm{a})$ & Digit-monitoring task & Readability rating task & $=$ & $=$ \\
\hline McGann et al., 2002-3 & $96(\mathrm{n} / \mathrm{a})$ & Digit-monitoring task & $\begin{array}{l}\text { Readability rating task } \\
\text { or pleasantness rating task }\end{array}$ & $\begin{array}{c}=\text { (readability } \\
\text { rating task })\end{array}$ & $=$ \\
\hline McDaniel et al., 2004-2 & $63(\mathrm{n} / \mathrm{a})$ & Digit-monitoring task & Word-rating task & 1 & $\mathrm{n} / \mathrm{a}$ \\
\hline McDaniel et al., 2008-1 & $34(\mathrm{n} / \mathrm{a})$ & Digit-monitoring task & Word-rating task & $=$ & $\mathrm{n} / \mathrm{a}$ \\
\hline Guynn \& McDaniel, 2007 & $82(\mathrm{n} / \mathrm{a})$ & Digit-monitoring task & Word-rating task & $\begin{array}{c}=\text { (preexposed } \\
\text { targets })\end{array}$ & $\mathrm{n} / \mathrm{a}$ \\
\hline Einstein et al., 1997-1 & $64(19.43 ; \mathrm{n} / \mathrm{a})$ & Digit-monitoring task & Word-rating task & $\downarrow$ & $\mathrm{n} / \mathrm{a}$ \\
\hline Einstein et al., 1997-2 & $64(19.50 ; \mathrm{n} / \mathrm{a})$ & Digit-monitoring task & Word-rating task & $=$ & $\mathrm{n} / \mathrm{a}$ \\
\hline Van den Berg et al., 2004-2 & $80(22 ; 5.3)$ & $\begin{array}{l}\text { Random interval generation task } \\
\text { (fixed or random tapping intervals) }\end{array}$ & $\begin{array}{l}\text { Short-term memory task } \\
+ \text { sentence construction task }\end{array}$ & $=$ & $\downarrow \%$ \\
\hline Boywitt et al., 2015-1 & $73(21.86 ; 2.15)$ & Tone-monitoring task & Lexical decision task & $=$ & $\downarrow \%$ and RTs \\
\hline Rummel et al., 2016-2 & $68(\mathrm{n} / \mathrm{a})$ & Tone-monitoring task & Word-categorization task & $=$ & $=\%$ and $\mathrm{RTs}$ \\
\hline Marsh \& Hicks, 1998-4 & $36(\mathrm{n} / \mathrm{a})$ & $\begin{array}{l}\text { Visuospatial task } \quad \text { (sequential } \\
\text { tapping task) }\end{array}$ & Short-term memory task & $\downarrow$ & $=\%$ \\
\hline Marsh \& Hicks, 1998-5 & $36(\mathrm{n} / \mathrm{a})$ & Visuospatial task (colored square task) & Short-term memory task & $=$ & $=\%$ \\
\hline Marsh \& Hicks, 1998-3 & $36(n / a)$ & Rehearse aloud monosyllabic words & Short-term memory task & $=$ & $\downarrow \%$ \\
\hline Van den Berg et al., 2004-3 & $80(21 ; 2.2)$ & $\begin{array}{l}\text { Random interval generation task } \\
\text { (fixed or random tapping intervals) }\end{array}$ & $\begin{array}{l}\text { Short-term memory task } \\
+ \text { sentence construction task }\end{array}$ & $=$ & $\downarrow \%$ \\
\hline \multicolumn{6}{|l|}{ WM executive processing } \\
\hline McDaniel et al., 2008-2 & $128(\mathrm{n} / \mathrm{a})$ & Random number generation & Word-rating task & 1 & $\downarrow \%$ and RTs \\
\hline McDaniel \& Scullin, 2010-2 & $72(\mathrm{n} / \mathrm{a})$ & Random number generation task & Category decision task & 1 & $\downarrow \%$ and RTs \\
\hline Harrison et al., 2014-2 & $56(\mathrm{n} / \mathrm{a})$ & Random number generation task & Lexical decision task & 1 & $\downarrow \%$ and RTs \\
\hline Harrison et al., 2014-3 & $64(\mathrm{n} / \mathrm{a})$ & Random number generation task & Lexical decision task & $\downarrow$ & $\downarrow \%$ and RTs \\
\hline McDaniel \& Scullin, 2010-1 & $64(\mathrm{n} / \mathrm{a})$ & Random number generation task & $\begin{array}{l}\text { Lexical decision task } \\
+ \text { category decision task }\end{array}$ & 1 & $\downarrow \%$ and RTs \\
\hline Marsh \& Hicks, 1998-2 & $54(\mathrm{n} / \mathrm{a})$ & Random number generation task & $\begin{array}{l}\text { Short-term memory task } \\
\text { (auditorily) }\end{array}$ & 1 & $\downarrow \%$ \\
\hline Van den Berg et al., 2004-1 & $91(21 ; 2.1)$ & Random number generation task & Short-term memory task & $=$ & $=\%$ \\
\hline \multicolumn{6}{|l|}{ Reasoning tasks } \\
\hline Logie et al., 2004 & $40(21.50 ; 2.4)$ & Arithmetic verification tasks & $\begin{array}{l}\text { Video watching for future } \\
\text { questions }\end{array}$ & 1 & $\mathrm{n} / \mathrm{a}$ \\
\hline \multicolumn{6}{|l|}{ LTM tasks } \\
\hline $\begin{array}{l}\text { Bisiacchi et al., 2008- } \\
\text { comparison between } 1 \text { and } 2\end{array}$ & $40(\mathrm{n} / \mathrm{a})$ & $\begin{array}{l}\text { LTM task (Memorize items for } \\
\text { future recall) }\end{array}$ & Picture-naming task & 1 & । RTs \\
\hline Einstein et al., 1995-3 & $\begin{array}{l}\text { YA: } 36(20.2 ; \mathrm{n} / \mathrm{a}) \\
\text { MA: } 28(42.5 ; \mathrm{n} / \mathrm{a})\end{array}$ & LTM task (Hear a story for future recall) & General knowledge questions & $=$ & $=\%$ \\
\hline Khan et al., 2008 & $80(24.61 ; 3.01)$ & LTM task (Hear a story for future recall) & General knowledge questions & 1 & $=\%$ \\
\hline d'Ydewalle et al., 1999 & $60(19.35 ; \mathrm{n} / \mathrm{a})$ & $\begin{array}{l}\text { LTM task (Memorize continuously the } \\
\text { last five presented questions or slides) }\end{array}$ & $\begin{array}{l}\text { Questions answering } \\
+ \text { face-identification task }\end{array}$ & $=$ & $=\%$ \\
\hline
\end{tabular}

Note . WM = Working memory; $\mathrm{PM}=$ Prospective memory; OT = Ongoing task; $\downarrow$ = Worse performance; $=$ Similar performance; $\mathrm{YA}=$ Younger adults; $\mathrm{MA}=$ Middle-age adults; $\mathrm{n} / \mathrm{a}=$ not available. 
tive odd digits (digit-monitoring WM task) while performing a primary verbal OT and holding a focal intention to press a designated key when target words appeared, revealed no statistically significant between-group differences in PM performance (Boywitt et al., 2015, Experiment 1; Rummel et al., 2016, Experiment 2). Indeed, in the study by Marsh and Hicks (1998), the authors only reported lower PM performance using a visuospatial task when it demanded more central executive resources.

Additionally, a deleterious effect on PM performance was reported in experiments adding a secondary random number generation task (Harrison et al., 2014, Experiments 2 and 3; Marsh \& Hicks, 1998, Experiment 2; McDaniel et al., 2008, Experiment 2; McDaniel \& Scullin, 2010, Experiment 1 and 2; van den Berg et al., 2004, Experiment 1). In such cases, participants were asked to perform a primary verbal task (i.e., word-rating and LDTs) while also generating random numbers, along with the intended action to press a key whenever some words appeared (i.e., a specific and focal PM cue). A similar finding was reported by Logie et al. (2004) when participants were asked to say animal when target images were presented, while watching a video and performing a concurrent reasoning task. Finally, experiments adding an LTM task showed inconsistent results: two of them indicated a disruptive effect on PM performance (Bisiacchi et al., 2008; Khan et al., 2008), while the others did not (d'Ydewalle et al., 1999; Einstein et al., 1995, Experiment 3). It is noteworthy, however, that three of the previous experiments (d'Ydewalle et al., 1999; Einstein et al., 1995, Experiment 3; Khan et al., 2008) did not clearly show an effective load manipulation as similar OT performance was obtained across groups.

\section{TASK-SWITCHING PROCEDURES}

The results concerning task-switching, that is, when participants had to engage in a single task versus when they had to switch between distinct activities, are shown in Table 3. Given that switching between different tasks is more demanding than repeating the same task across time (Monsell, 2003), the comparison between these experimental conditions is a way of exploring how cognitive load may affect PM performance (Pereira et al., 2018). All task-switching studies included here used an OT involving semantic processing. As a main finding, most of them revealed that young adults performed poorly in the EBPM task when they had to switch between tasks relative to when they had to repeat the same task (Marsh et al., 2002; McNerney \& West, 2007; West et al., 2011, Experiment 1). Even so, Pereira et al. (2018) did not find a PM impairment.

Also, most of these experiments used focal and non-salient PM cues (i.e., press a designated key when target words appear while making judgments; Marsh et al, 2002; McNerney \& West, 2007; West et al., 2011, Experiment 1). Even though focal PM cues were utilised, these experiments revealed a lower PM performance when participants were required to switch between tasks compared to when they were engaged in a single task (see Tables S1-S3 in the Supplementary Material).

\section{OTHER RELEVANT FACTORS}

Besides the type of cognitive load manipulation (i.e., increasing the difficulty of the OT; adding a secondary OT; task-switching), other factors to consider are the type of design used to operationalize such manipulation (i.e., between-subjects or within-subjects design), focality of the PM cue (i.e., focal or non-focal), and PM cue salience (i.e., salient or non-salient). In this regard, the effect of demanding OTs on EBPM omission errors was reported in both experiments using between-subjects (e.g., Logie et al., 2004; Marsh \& Hicks, 1998, Experiments 1 and 3; McGann et al., 2002) and within-subjects designs (e.g., Harrison et al., 2014, Experiment 3 and 4; McDaniel et al., 2008; West \& Bowry, 2005).

Given that focal and salient PM cues have been shown to promote an automatic retrieval of the delayed intentions, leading to a better PM performance (McDaniel \& Einstein, 2000), it was expected that PM performance under demanding conditions would be protected by using focal and salient PM cues. Although only a small number of studies fulfil these criteria, the ones available reported no PM impairment under complex task processing when both criteria were met (Boywitt et al., 2015; West et al., 2006). Still, salient and focal PM cues did not help to accurately perform a delayed intention in complex situations requiring WM and attentional executive processes (Harrison et al., 2014, Experiment 3). This finding, however, requires further examination in future studies and should be interpreted with caution as only a few experiments used salient and focal PM cues. Taken together, the evidence in this domain remains scarce, and more studies are needed to explore possible interactive effects between the focality and/or the saliency of the PM cue and the OT load.

\section{SUMMARY OF EVENT-BASED PROSPECTIVE MEMORY TASK RESULTS}

To date, 26/56 experiments that used EBPM performance under demanding conditions showed a PM decrement, and 30/56 did not. There is substantial evidence suggesting a deleterious effect on young adults' ability to execute a delayed intention when there is an increase in the primary OT difficulty, when a secondary task is added, or when participants are required to engage in task-switching conditions. The critical element that appears to be shared by the former tasks is the requirement of WM attentional executive resources during the OT processing. Conversely, increasing the demands of the ongoing activities by overloading the WM storage does not seem to impair PM performance. Moreover, although salient and focal cues seem to support PM performance under demanding conditions, they do not help accurately perform a delayed intention in complex situations such as the ones implying WM executive processes.

\section{Time-Based Prospective Memory Tasks}

Table 4 shows data regarding omission errors in TBPM tasks. Results demonstrate an impaired PM performance with reasoning tasks (Martin \& Schumann-Hegsteler, 2001) or by adding a secondary arithmetic verification task (Logie et al., 2004) while monitoring to press the spacebar or to change the protocol sheet every three minutes, re- 
TABLE 3.

Experiments on the Effect of Cognitive Load in Event-Based Prospective Memory Omission Errors in Task-Switching Paradigms

\begin{tabular}{|c|c|c|c|c|}
\hline \multirow{2}{*}{ Experiment } & \multirow{2}{*}{$\begin{array}{c}\text { Sample } N \\
(\text { age- } M ; S D)\end{array}$} & \multirow{2}{*}{ Ongoing task } & \multicolumn{2}{|c|}{ Key findings } \\
\hline & & & PM & OT \\
\hline Marsh et al., 2002-1 and 2 & $157(\mathrm{n} / \mathrm{a})$ & $\begin{array}{l}\text { Judgment word task (Experiment1: Long E-sound vs. animacy judgment; } \\
\text { Experiment 2: Count the number of syllables vs. invert interchanged letters) }\end{array}$ & $\downarrow$ & $\downarrow$ RTs \\
\hline McNerney \& West, 2007-1 & $20(20.22 ; \mathrm{n} / \mathrm{a})$ & Judgment word task (noun or verb vs. 1 or 2 vowels) & $\downarrow$ & $\downarrow$ RTs \\
\hline McNerney \& West, 2007-2 & $32(19.78 ; \mathrm{n} / \mathrm{a})$ & Judgment word task (noun or verb vs. 1 or 2 vowels) & $\downarrow$ & $\downarrow$ RTs \\
\hline McNerney \& West, 2007-3 & $26(19.39 ; \mathrm{n} / \mathrm{a})$ & Judgment word task (noun or verb vs. 1 or 2 vowels) & $\downarrow$ & $\downarrow$ RTs \\
\hline West et al., 2011-1 & $24(21.70 ; 7.38)$ & Judgment word task (noun or verb vs. 1 or 2 vowels) & $\downarrow$ & $\downarrow \%$ and RTs \\
\hline West et al., 2011-2 & $21(19.55 ; 1.19)$ & Judgment word task (noun or verb vs. 1 or 2 vowels) & $=$ & $\downarrow$ RTs \\
\hline Pereira et al., 2018 & $32(21.75 ; 4.30)$ & Lexical decision task + capital decision task & $=$ & $\downarrow$ RTs \\
\hline
\end{tabular}

Note. $\mathrm{PM}=$ Prospective memory; $\mathrm{OT}=$ Ongoing task; $\downarrow$ = Worse performance; $=$ Similar performance.

\section{TABLE 4.}

Experiments on the Effect of Cognitive Load in Time-Based Prospective Memory Omission Errors

\begin{tabular}{|c|c|c|c|c|c|}
\hline \multirow{2}{*}{ Experiment } & \multirow{2}{*}{$\begin{array}{c}\text { Sample } N \\
\text { (age- } M ; S D)\end{array}$} & \multirow{2}{*}{ Ongoing task } & \multirow{2}{*}{ Secondary ongoing task } & \multicolumn{2}{|c|}{ Key findings } \\
\hline & & & & PM & OT \\
\hline \multicolumn{6}{|c|}{ Experiments varying ongoing task difficulty } \\
\hline $\begin{array}{l}\text { Martin \& Schumann- } \\
\text { Hengsteler, } 2001\end{array}$ & $90(24.0 ; 3.77)$ & Mastermind task & - & $\downarrow$ & $\downarrow$ \\
\hline Gonneaud et al., 2011 & $\begin{array}{l}\text { YA: } 29(24.3 ; 4.5) \\
\text { MA: } 20(51 ; 7)\end{array}$ & Mental addition task & - & $=$ & $\mathrm{n} / \mathrm{a}$ \\
\hline Fronda et al., 2020 & $21(29 ; 8)$ & Mental arithmetic task & - & $=$ & $\downarrow \%$ \\
\hline \multicolumn{6}{|c|}{ Experiments adding a secondary ongoing task } \\
\hline Khan et al., 2008 & $80(26.41 ; 3.01)$ & General knowledge questions & Hear a story for future recall & $\downarrow$ & $=$ \\
\hline Einstein et al., 1995-3 & $\begin{array}{l}\text { YA: } 36(20.2 ; \mathrm{n} / \mathrm{a}) \\
\text { MA: } 28(42.5 ; \mathrm{n} / \mathrm{a})\end{array}$ & $\begin{array}{l}\text { General knowledge and } \\
\text { problem-solving questions }\end{array}$ & Hear a story for future recall & $=$ & $=$ \\
\hline Logie et al., 2004 & $40(21.05 ; 2.4)$ & $\begin{array}{l}\text { Long-term memory task (video } \\
\text { watching for future questions) }\end{array}$ & Arithmetic verification task & $\downarrow$ & $\mathrm{n} / \mathrm{a}$ \\
\hline d’Ydewalle et al., 1999 & $60(19.35 ; \mathrm{n} / \mathrm{a})$ & $\begin{array}{l}\text { Questions answering vs. face- } \\
\text { identification task }\end{array}$ & $\begin{array}{l}\text { Short-term memory task } \\
\text { (memorize continuously the } \\
\text { general theme of the last five } \\
\text { questions) }\end{array}$ & $=$ & $=$ \\
\hline
\end{tabular}

Note. $\mathrm{PM}=$ Prospective memory; $\mathrm{OT}=$ Ongoing task; $\downarrow$ = Worse performance; = Similar performance; YA = Younger adults; $\mathrm{MA}=$ Middle-age adults; $\mathrm{n} / \mathrm{a}=$ not available.

spectively. In contrast, d'Ydewalle et al. (1999) and Einstein et al. (1995, Experiment 3) also added a secondary task, yielding nonsignificant differences in PM performance. Even so, the OT performance did not differ across groups which may suggest that the ongoing manipulation did not increase the cognitive load to the point of affecting the ability to carry out the intended action. As an alternative, it could be the case in other experiments that participants maintained a stable OT execution by dampening their PM task response. Thus, PM performance was significantly affected due to a trade-off between PM and OTs (Khan et al., 2008; Logie et al., 2004).

Moreover, when the effect of OT load was observed, it was irrespective of the experimental design (between-subjects: Logie et al., 2004; Martin \& Schumann-Hengsteler, 2001; within-subjects: Khan et al., 2008; see Table S4 in the Supplementary Material). Also, it is worth mentioning that the analysis of time-checking frequency revealed that participants check the clock to remind themselves about the PM task more often in low-load conditions than in high-load conditions (Gonneaud et al., 2011; Khan et al., 2008).

\section{SUMMARY OF TIME-BASED PROSPECTIVE MEMORY TASK RESULTS}

Overall, the same pattern of PM impairment was found in 3/7 experiments that investigated TBPM task performance under cognitively demanding activities. That is, regardless of OT manipulation, PM performance was hindered if participants were cognitively overloaded by ongoing activities that were more demanding in terms of executive WM resources.

\section{DISCUSSION}

The present review aimed to synthetize the large body of literature on the role OT demands on PM performance and to interpret those 
findings while considering the nature of the OT load manipulation in order to identify directions for future research. There were two main findings. First, resource-demanding OT processing may pose serious threats to the execution of delayed EBPM and TBPM intentions (e.g., Harrison et al., 2014; Lewis-Peacock et al., 2016; Logie et al., 2004; McDaniel \& Scullin, 2010). Second, it seems that the efficiency of PM is likely disturbed the more the OT recruits WM and executive resources (Marsh \& Hicks, 1998).

\section{Prospective Memory Omission Errors: Increasing Ongoing Task Complexity Impairs Prospective Memory Detection}

The evidence presented so far indicates that we are likely to forget to perform a previously planned intention whilst engaged in resourcedemanding concurrent activities (see Figure 2). First, regarding EBPM tasks, OTs involving greater monitoring (e.g., arithmetic task, visuospatial monitoring, counting, and random number generation) or planning component affected PM performance (Lewis-Peacock et al., 2016; Harrison et al., 2014, Experiments 2 and 3; Marsh \& Hicks, 1998, Experiment 2; McDaniel et al., 2008, Experiment 2; McDaniel \& Scullin, 2010, Experiments 1 and 2; Möschl et al., 2019; Stone et al., 2001; West \& Bowry, 2005). These tasks likely overloaded WM and executive resources, particularly when participants were required to inhibit stereotypic sequences (e.g., 1-2-3, 2-4-6) while monitoring their output to comply with the randomness condition (Baddeley et al., 1998). These findings are consistent with prior research indicating that poor PM performance is linked to impaired WM (Arnold et al., 2015; Rose et al., 2010), planning (e.g., Shum et al., 2013), inhibition, or task-switching abilities (e.g., Schnitzspahn et al., 2013).

In contrast, the OT processing of visuospatial information (e.g., colour-matching task; Horn et al., 2011; Lee \& McDaniel, 2013; Smith et al., 2012; Smith \& Hunt, 2014; see Table 2) or the maintenance of verbal information (e.g., word study and recall; Otani et al., 1997) did not yield significant differences on PM performance between low- and high-load conditions. The same pattern was documented in those experiments adding a digit-monitoring task to the primary OT (Boywitt et al., 2015, Experiment 1; Einstein et al., 1997, Experiment 2; Guynn \& McDaniel, 2007; Harrison et al., 2014, Experiment 1; McDaniel et al., 2008, Experiment 1). In this case, although monitoring for odd numbers probably drew attentional resources, one could argue that this condition did not impose enough load on WM and executive abilities. Thus, this allowed for effective management of the available resources to accomplish the PM task.

Moreover, the empirical evidence indicates that when the OT resource demands are varied within the context of a task-switching paradigm (i.e., with the idea that switch blocks would demand greater attentional resources than repetition of a single task across time) PM suffers (Marsh et al., 2002; McNerney \& West, 2007; West et al., 2011). Yet, Pereira et al. (2018) did not replicate this result. In this case, the authors suggested that the cognitive load imposed by the two OTs used (i.e., perceptual task vs. LDT) may not have reached a similar level of demand as in previous studies. Thus, no effect on PM performance was detected in this case. The cognitive load imposed by task-switching conditions is based on the notion that additional cognitive processing resources are required to suppress responding to the OT and to execute the PM task. In this vein, McNerney and West (2007) argued that the effect of task-switching on PM might not result from the specific requirement to switch between task sets (i.e., different judgments made from one trial to the next). Instead, it may arise from the requirement to manage multiple task sets that are held in WM to guide task performance. For instance, in a task wherein participants must indicate whether a word is a noun or a verb or whether a word has one or two vowels, they must keep two different task sets online: The grammatical class task set, and the number of vowels task set. Arguably, this idea fits with the notion that increased load on central executive processes might contribute to the PM decrease in task-switching conditions.
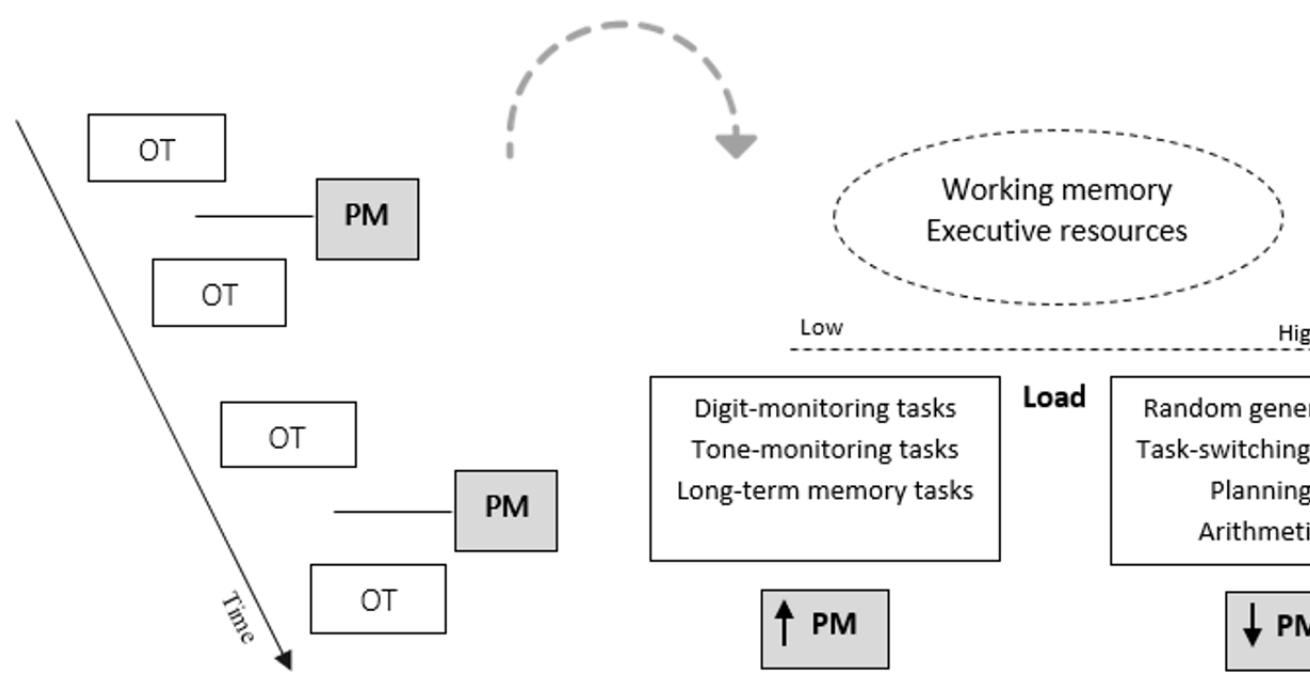

FIGURE 2.

Schematic diagram showing the effect of ongoing task load on event-based and time-based prospective memory performance. PM = prospective memory; OT = ongoing task. 
Second, TBPM performance was also modulated by the demands imposed by the concurrent activities (Khan et al., 2008; Logie et al., 2004). That is, the successful recall and enactment of TBPM intentions may be disturbed when the intentions are not being retrieved or available in WM, but also when the ease of disengagement from the OT is affected. Nevertheless, this result should be treated with caution as only a few studies using TBPM tasks were conducted. Both EBPM and TBPM performance appear be sensitive to the type of demands placed on the cognitive system when an intention-related cue is encountered. Given that TBPM tasks rely more on shifting abilities (Kliegel et al., 2003) and on controlled and costly monitoring processes than EBPM tasks (Henry et al., 2004), it would be reasonable to assume that TBPM (as opposed to EBPM) tasks might be more affected by manipulations on OT load. Still, the dearth of evidence regarding the comparison between TBPM and EBPM performance (e.g., Fronda et al., 2020; Khan et al., 2008) highlight the need to further test this hypothesis.

Lastly, in addition to the overall demands that are required by an OT, we now consider how those processing manipulations interact with the processing that would be required to identify a PM cue (Marsh et al., 2000). As previously stated, focal and salient PM cues should increase the involvement of automatic processing in prospective remembering, rendering performance less susceptible to load effects. Kidder et al. (1997) used non-focal and non-salient PM cues, which likely imposed an active monitoring strategy as the cognitive resources required to perform the OT did not match the types of cognitive resources needed to identify the cue, nor did the OT make aspects of the PM cue salient. So, the lack of processing resources to retrieve the planned intention when the OT must be disengaged might explain why participants tended to fail PM execution during a verbal WM task that, theoretically, would impose a load on WM storage rather than on executive processes. In other cases, salience and/or focality of the PM cue may be able to counteract the deleterious effects of limited processing resources (Marsh et al., 2002; West et al., 2006; see also Marsh et al., 2000). For example, in the West et al. (2006) study, the PM cue was salient and focal which may have promoted PM retrieval even though participants performed a demanding $n$-back task. Still, despite using focal or salient PM cues, most studies revealed that PM was susceptible to OT regardless of the qualitative processing of PM cues. However, to determine how the content of a delayed intention may interact with different degrees of OT load is a question for future research.

\section{Ongoing Task Load and Prospective Memory Commission Errors: A New Avenue of Research}

Less is known about the role of demanding OTs on PM deactivation (see Table 5). Surprisingly, there is growing evidence that, under conditions of heavy cognitive load or distraction, participants may continue to perform a previously planned intention when they no longer have to do so (Boywitt et al., 2015, Experiment 1; Matos et al., 2020; Pink \& Dodson, 2013). These memory failures, termed as PM commission errors, are thought to occur when participants spontaneously notice the PM cue and fail to inhibit PM execution (Bugg et al., 2016; Scullin et al., 2012; Schaper \& Grundgeiger, 2019). This can be observed, for example, in some studies (Boywitt et al., 2015, Experiment 1; Matos et al., 2020; Pink \& Dodson, 2013, Experiments 1a and 1b) adding tone-monitoring, digit-monitoring or counting recall tasks to an LDT in which focal PM cues were embedded (i.e., pressing a key when target words were detected). Thus, the finding that more participants make more commission errors as a function of increasing OT complexity is in line with the idea that an inefficient management of the available resources - that also serve to inhibit irrelevant information - is responsible for this type of PM failures (Bugg et al., 2016; Cowan, 2017; Engle, 2002). Moreover, the salience and focality of the PM cues might have also accounted for the increased number of commission errors observed (Bugg et al., 2016; Scullin \& Bugg, 2013; see Table S5 in the Supplementary Material). However, the scarce number of studies in this field underscores the need to better examine the role of cognitive load and PM cue salience on PM commission errors in order to clarify which conditions may be more prone to the occurrence of such memory failures.

\section{Theoretical Implications}

Notably, the earliest studies on divided attention and PM pinpointed the importance of considering whether the OT demands impact the executive processing or whether they simply induce an increase in storage load (e.g., Marsh \& Hicks, 1998; Otani et al., 1997). For instance, Marsh and Hicks (1998) reported that changing the difficulty of the OT without a deeper involvement of WM and executive control was insufficient to affect young adults' PM ability in EBPM tasks. The current systematic review provided support for this claim, which may shed some light on the discrepant findings reported in the literature.

As stated, cognitive load manipulations require participants to orient and manage their cognitive resources to respond effectively to both the ongoing and the PM task. To achieve that, WM resources and executive functions of inhibition are needed not only to hold information temporarily in a heightened state of availability for performing both tasks (see Cowan, 2017), but also to keep WM (i.e., the focus of attention) free from irrelevant information (see Hasher et al., 2007 for further details). However, WM capacity only allows for holding a limited amount of information. Thus, imposing higher demands through arithmetic, random number generation (e.g., Harrison et al., 2014, Experiments 2 and 3; Logie et al., 2004; Marsh et al., 2002), planning (Stone et al., 2001), or task-switching tasks (Marsh et al., 2002; McNerney \& West, 2007; West et al., 2011) has a deleterious effect on PM performance as there are fewer resources available to support PM retrieval when the associated PM cue is encountered. In such highload conditions, the competition for WM and executive resources and the need for goal prioritization resulted in worse PM performance when compared to low-load conditions. On the contrary, when participants were engaged in less effortful tasks requiring storage of verbal or visual information, no PM decline was observed (e.g., Einstein et al., 1995, Experiment 3; Harrison et al., 2014, Experiment 1; Horn et al., 2011; Otani et al., 1997; Rendell et al., 2007, Experiment 2; Smith \& Hunt, 2014). 
TABLE 5.

Experiments on the Effect of Cognitive Load in Event-Based and Time-Based Prospective Memory Commission Errors

\begin{tabular}{|c|c|c|c|c|c|}
\hline \multirow{2}{*}{ Experiment } & \multirow{2}{*}{$\begin{array}{c}\text { Sample } N \\
(\text { age- } M ; S D)\end{array}$} & \multirow{2}{*}{ Ongoing task } & \multirow{2}{*}{ Secondary ongoing task } & \multicolumn{2}{|c|}{ Key findings } \\
\hline & & & & PM & OT \\
\hline \multicolumn{6}{|c|}{ Event-based prospective memory tasks } \\
\hline Boywitt, et al., 2015-1 & $73(21.86 ; 2.15)$ & Lexical decision task & Tone-monitoring task & $!$ & $\downarrow \%$ and RTs \\
\hline $\begin{array}{l}\text { Pink \& Dodson, 2013- } \\
\text { la and } 1 \mathrm{~b}\end{array}$ & $\begin{array}{l}96 \text { in each } \\
\text { experimental } \\
\text { condition }\end{array}$ & Lexical decision task & Digit-monitoring task & 1 & $=$ \\
\hline Matos et al., 2020 & $140(21.22,4.27)$ & Lexical decision task & Counting-recall task & 1 & $\downarrow \%$ \\
\hline \multicolumn{6}{|c|}{ Time-based prospective memory tasks } \\
\hline Einstein et al., 1998 & $63(19.8 ; 2.58)$ & $\begin{array}{l}\text { Different tasks (vocabulary; implicit memory; } \\
\text { internal source monitoring; perceptual speed; } \\
\text { action control; compulsivity) }\end{array}$ & Digit-monitoring task & $=$ & $\mathrm{n} / \mathrm{a}$ \\
\hline
\end{tabular}

Note. PM = Prospective memory; $\mathrm{OT}=$ Ongoing task $\mathrm{E}=$ Event-based task $\mathrm{T}$ = Time-based task; $\downarrow$ = Worse perfor-

mance; $=$ Similar performance; $\mathrm{n} / \mathrm{a}=$ not available .

Moreover, in a series of experiments, Baddeley et al. (1984) demonstrated that retrieval from LTM did not appear to depend heavily on executive resources. In line with this idea, cognitive load manipulations on LTM tasks did not influence PM performance (see Einstein et al., 1995, Experiment 3; d'Ydewalle et al., 1999; Rendell et al., 2007, Experiment 2). Indeed, different brain mechanisms appear to underly WM and episodic memory functions. Tasks relying on the central executive tend to recruit prefrontal and parietal brain regions (Collette \& Van der Linden, 2002; Cona et al., 2015), whereas the encoding and successful retrieval of episodic memories require the additional involvement of medial temporal areas (Dickerson \& Eichenbaum, 2010; Rugg \& Vilberg, 2013). Taken together, the tasks that resulted in PM decrements required more difficult monitoring, planning, inhibition, and task-switching resources to avoid making errors. These results lend further support to the notion that PM requires resources of the same type that contribute to successful OT performance, presumably due to the contribution of the WM and executive control processes. When those demands are great enough, decrements in prospective responding are observed.

\section{Limitations and Future Research}

First, some experiments reported a similar OT performance between low- and high-load conditions (e.g., Harrison et al., 2014, Experiment 1; Marsh \& Hicks, 1998, Experiment 4 and 5; McGann et al., 2002, Experiment 3), which could be explained by an ineffective load manipulation. Even so, PM performance was impaired in some of the former studies (e.g., Marsh \& Hicks, 1998, Experiment 4). Thus, as PM cues are always embedded in an OT, it is possible that a trade-off occurred between PM and OT performance. Put differently, if more resources were devoted to the ongoing activity, fewer would be available to execute the planned intention leading to a worse PM performance (e.g., d'Ydewalle et al., 1999). Yet, Marsh and Hicks (1998, Experiment 2) did not find that participants traded accuracy in the OT to better perform the PM task, as they performed at a similar level on both conditions. In this case, perhaps the focality of the PM cue (or the strength of the association between the cue and the intention) was able to counteract the deleterious effects of fewer processing resources (McDaniel
\& Einstein, 2007). Thus, trade-off effects, as well as cue focality and salience, should be further considered in future studies. Moreover, since we observed no PM impairment despite cross-modality between PM and OT (e.g., Boywitt et al., 2015; Fronda et al., 2020; Otani et al., 1997), a better understanding of how congruent multisensory processes may up-regulate (or benefit) PM cue detection under complex conditions is another promising topic for future research (Bonnici et al., 2016; Barutchu et al., 2019).

Second, we did not include studies exploring the effects of cognitive load beyond EBPM and TBPM tasks, such as activity-based tasks. However, it is worth noting that the first two typically require the interruption of an OT, whereas activity-based intentions must be completed between tasks (e.g., return a book to the library immediately after the class; Brewer et al., 2011). Thus, future reviews should also probe the role of OT load on these activity-based intentions as its impact might differ according to the type of PM task. Finally, most of the studies included in this review implemented cognitive load manipulation within the timeframe required to carry out the intention (i.e., performance interval; see Ellis, 1996; Kliegel et al., 2002). In this context, an avenue for future research would be to examine whether PM performance is vulnerable to the interference prompted by demanding conditions placed during PM encoding or during the delay interval between encoding and PM retrieval.

\section{Conclusions}

The present study was the first systematic review exploring the effects of cognitive load on young and middle-aged adults' prospective remembering. There was substantial evidence indicating that PM performance was hindered when cognitive resources were progressively captured by a difficult OT, by higher demands of a secondary task, or by task-switching conditions. A novel and counterintuitive finding was that, under demanding situations, one could also erroneously perform an intention which is no longer needed. Moreover, this review highlighted the crucial role of WM and executive demands required by OTs, as well as the characteristics of the PM cue, in predicting the successful accomplishment of PM intentions. 


\section{FOOTNOTES}

${ }^{1}$ When the OT processing overlaps highly with PM task processing, the PM task is considered focal. On the contrary, when the processing overlap is low, the task is considered non-focal. For instance, in an LDT which requires the assessment of the semantic features of a string of letters, a focal PM task would be to press a key to a specific word (i.e., rake). It would be focal because determining whether a string of letters is a word or not encourages the semantic processing of the word, which aligns with the processing required to detect the PM cues. A non-focal task, in turn, would be to press a key if the string of letters contains a specific syllable. In this case, the detection of the PM cues would require the syllabic processing of the words, which differs from the semantic processing required by the LDT (Cona et al., 2016; Einstein \& McDaniel, 2005; Uttl, 2011).

\section{ACKNOWLEDGEMENTS}

This project was founded by the Portuguese Foundation for Science and Technology (FCT, Portugal) with the grant BD/123421/2016 awarded to Patrícia Matos and with the grant PD/ BD/105964/2014 awarded to Diana R. Pereira. This study was conducted at the Psychology Research Centre (UID/PSI/01662/2019), University of Minho, and supported by the Portuguese Ministry of Science, Technology and Higher Education, through the State Budget (UID/PSI/01662/2019). Correspondence concerning this article should be addressed to Patrícia Fernanda Ferreira Matos, School of Psychology, University of Minho, Campus de Gualtar, 4710-057 Braga, Portugal.

\section{REFERENCES}

Studies marked with an asterisk were included in the systematic review.

Albinski, R., Kliegel, M., Sedek, G., \& Kleszczewska-Albinska, A. (2012). Positive effects of subclinical depression in prospective memory and ongoing tasks in young and old adults. Aging, Neuropsychology, and

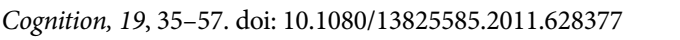

Anderson, F. T., \& McDaniel, M. A. (2019). Retrieval in prospective memory: Multiple processes or just delay? Quarterly Journal of Experimental Psychology, 72, 2197-2207. doi: 10.117L7/1747021819845622

Anderson, F. T., Strube, M. J., \& McDaniel, M. A. (2019). Toward a better understanding of costs in prospective memory: A meta-analytic review. Psychological Bulletin, 145, 1053-1081. doi: 10.1037/ bul0000208 الس السلس

Arnold, N. R., Bayen, U. J., \& Smith, R. E. (2015). Hierarchical multinomial modelling approaches: An application to prospective memory and working memory. Experimental Psychology, 62, 143-152. doi: 10.1027/1618-3169/a000287

Baddeley, A. (1986). Working memory. Oxford University Press.

Baddeley, A. (1996). Exploring the central executive. The Quarterly Journal of Experimental Psychology, 49, 5-28. doi: 10.1080/027249896392784 الس السلس

Baddeley, A., Emslie, H., Kolodny, J., \& Duncan, J. (1998). Random generation and the executive control of working memory. The Quarterly Journal of Experimental Psychology, 51A, 819-852. doi: 10.1080/713755788 السلسلس

Baddeley, A., Lewis, V., Eldridge, M., \& Thomson, N. (1984). Attention and retrieval from long-term memory. Journal of Experimental Psychology General, 113, 518-540. doi: 10.1037/0096-3445.113.4.518 سلس

Ballhausen, N., Schnitzspahn, K. M., Horn, S. S., \& Kliegel, M. (2017). The interplay of intention maintenance and cue monitoring in younger and older adults' prospective memory. Memory and Cognition, 45, 1113-1125. doi: 10.3758/s13421-017-0720-5 5

Barner, C., Seibold, M., Born, J., \& Diekelmann, S. (2016). Consolidation of prospective memory: Effects of sleep on completed and reinstated intentions. Frontiers in Psychology, 7, 2025. doi:

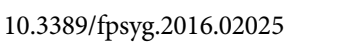

${ }^{*}$ Barutchu, A., Sahu, A., Humphreys, G. W., \& Spence, C. (2019). Multisensory processing in event-based prospective memory. Acta Psychologica, 192, 23-30. doi: 10.1016/j.actpsy.2018.10.015 السلسلسلس

Basso, D., Ferrari, M., \& Palladino, P. (2010). Prospective memory and working memory: Asymmetrical effects during frontal lobe TMS stimulation. Neuropsychologia, 48, 3282-3290. doi: 10.1016/j.neuropsychologia.2010.07.011 المالسلبل

${ }^{*}$ Bisiacchi, P. S., Tarantino, V., \& Ciccola, A. (2008). Aging and prospective memory: The role of working memory and monitoring processes. Aging, Clinical, and Experimental Research, 20, 569-577. doi: $10.1007 / \mathrm{bf} 03324886$ سلس

Bonnici, H. M., Richter, F. R., Yazar, Y., \& Simons, J. S. (2016). Multimodal feature integration in the angular gyrus during episodic and semantic retrieval. Journal of Neuroscience, 36, 5462-5471. doi: 10.1523/JNEUROSCI.4310-15.2016 1ل

${ }^{\star}$ Boywitt, C. D., Rummel, J., \& Meiser, T. (2015). Commission errors of active intentions: The roles of aging, cognitive load, and practice. Aging, Neuropsychology, and Cognition, 22, 560-576. doi: 10.1080/13825585.2014.1002446 1ل

Brewer, G. A., Ball, B. H., Knight, J. B., Dewitt, M. R., \& Marsh, R. L. (2011). Divided attention interferes with fulfilling activity-based intentions. Acta Psychologica, 138, 100-105. doi: 10.1016/j.actpsy.2011.05.011 السلسلس

Bugg, J. M., Scullin, M. K., \& Rauvola, R. S. (2016). Forgetting no-longer-relevant prospective memory intentions is (sometimes) harder with age but easier with forgetting practice. Psychology and Aging, 31, 358369. doi: 10.1037/pag0000087 السلسلس

Cheie, L., MacLeod, C., Miclea, M., \& Visu-Petra, L. (2017). When children forget to remember: Effects of reduced working memory availability on prospective memory performance. Memory and Cognition, 45, 651-663. doi: 10.3758/s13421-016-0682-z z لالسلسلس

Cohen, A. L. (2013). Attentional decoupling while pursuing intentions: A form of mind wandering? Frontiers in Psychology, 4, 693. doi:

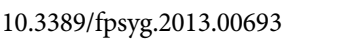

Cohen, A. L. (2017). The many faces of working memory and shortterm memory. Psychonomic Bulletin and Review, 24, 1158-1170. doi:

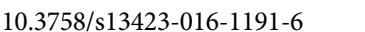

Collette, F., \& Van der Linden, M. (2002). Brain imaging of the 
central executive component of working memory. Neuroscience and Biobehavioral Reviews, 26, 105-125. doi: 10.1016/S01497634(01)00063-X 16لس

Cona, G., Bisiacchi, P. S., Sartori, G., \& Scarpazza, C. (2016). Effects of cue focality on the neural mechanisms of prospective memory: A meta-analysis of neuroimaging studies. Scientific Reports, 6, 25983. doi: 10.1038/srep25983 السلسلسلس

Cona, G., Scarpazza, C., Sartori, G., Moscovitch, M., \& Bisiacchi, P. S. (2015). Neural bases of prospective memory: A meta-analysis and the "Attention to Delayed Intention" (AtoDI) model. Neuroscience and Biobehavioral Reviews, 52, 21-37. doi: 10.1016/j.neubiorev.2015.02.007 المالسلسلس

Covidence (2015). Covidence systematic review software. Veritas

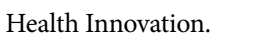

Cowan, N. (2017). The many faces of working memory and shortterm storage. Psychonomic Bulletin \& Review, 24, 1158-1170. doi: 10.3758/s13423-016-1191-6

Dickerson, B. C., \& Eichenbaum, H. (2010). The episodic memory system: Neurocircuitry and disorders. Neuropsychopharmacology, 35, 86-104. doi: 10.1038/npp.2009.126 المالسلس

*d'Ydewalle, G., Luwel, K., \& Brunfaut, E. (1999). The importance of on-going concurrent activities as a function of age in time- and event-based prospective memory. European Journal of Cognitive Psychology, 11, 219-237. doi: 10.1080/713752309 الملسلس

Einstein, G. O., \& McDaniel, M. A. (1990). Normal aging and prospective memory. Journal of Experimental Psychology. Learning, Memory,

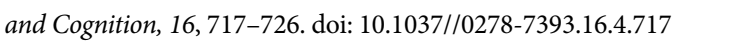

Einstein, G. O., \& McDaniel, M. A. (1996). Retrieval processes in prospective memory: Theoretical approaches and some new empirical findings. In M. Brandimonte, G. O. Einstein, \& M. A. McDaniel (Eds.), Prospective memory: Theory and applications (pp. 115-141). Lawrence Erlbaum Associates. Einstein, G. O., \& McDaniel, M. A. (2005). Prospective memory: Multiple retrieval processes. Current Directions in Psychological Science, 14, 286-291. doi: 10.1111/j.0963-7214.2005.00382.x المالسلسلة

Einstein, G. O., \& McDaniel, M. A. (2010). Prospective memory and what costs do not reveal about retrieval processes: A commentary on Smith, Hunt, McVay, and McConnell (2007). Journal of Experimental Psychology: Learning, Memory, and Cognition, 36, 1082-1088. doi: 10.1037/a0019184 المالسلسلة

${ }^{\star}$ Einstein, G. O., McDaniel, M. A., Richardson, S. L., Guynn, M. J., \& Cunfer, A. R. (1995). Aging and prospective memory: Examining the influences of self-initiated retrieval processes. Journal of Experimental Psychology: Learning, Memory, and Cognition, 21,

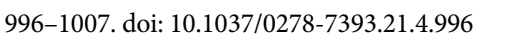

${ }^{\star}$ Einstein, G. O., McDaniel, M. A., Smith, R. E., Shaw, P. (1998). Habitual prospective memory and aging. Remembering intentions and forgetting actions Psychological Science, 9, 284-288. doi:

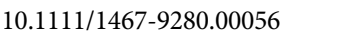

${ }^{\star}$ Einstein, G. O., Smith, R. E., McDaniel, M. A., \& Shaw, P. (1997). Aging and prospective memory: The influence of increased task demands at encoding and retrieval. Psychology and Aging, 12, 479-488. doi: 10.1037/0882-7974.12.3.479 سلس

Ellis, J. (1996). Prospective memory or the realization of delayed inten- tions: A conceptual framework for research. In M. Brandimonte, G. O. Einstein, \& M. A. McDaniel (Eds.), Prospective memory: Theory and applications (pp. 115-142). Lawrence Erlbaum Associates.

Engle, R. W. (2002). Working memory capacity as executive attention. Current Directions in Psychological Science, 11, 19-23. doi:

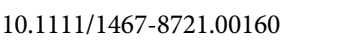

${ }^{\star}$ Fronda, G., Monti, C., Sozzi, M., Corbo, M., \& Balconi, M. (2020). Prospective memory and working memory in comparison. New experimental paradigms. International Journal of Neuroscience. Advance

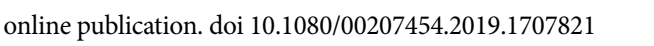

${ }^{\star}$ Gonneaud, J., \& Kalpouzos, G., Bon, L., Viader, F., Eustache, F., \& Desgranges, B. (2011). Distinct and shared cognitive functions mediate event- and time-based prospective memory impairment in normal ageing. Memory, 19, 360-377. doi: 10.1080/09658211.2011.570765 المالسلس

${ }^{\star}$ Guynn, M. G., \& McDaniel, M. A. (2007). Target preexposure eliminates the effect of distraction on event-based prospective memory. Psychonomic Bulletin and Review, 14, 484-488. doi: 10.3758/bf03194094 السلسلسلس

${ }^{\star}$ Harrison, T. L., Mullet, H. G., Whiffen, K. N., Ousterhout, H., \& Einstein, G. O. (2014). Prospective memory: Effects of divided attention on spontaneous retrieval. Memory and Cognition, 42, 212-224. doi: 10.3758/s13421-013-0357-y لسلسلس

Hasher, L., Lustig, C., \& Zacks, R. (2007). Inhibitory mechanisms and control of attention. In A. R. A. Conway, C. Jarrold, M. J. Kane, A. Miyake, \& J. N. Towse (Ed.), Variation in working memory (pp. 227-249): Oxford University Press.

Henry, J. D., MacLeod, M. S., Phillips, L. H., \& Crawford, J. R. (2004). A meta-analytic review of prospective memory and aging. Psychology

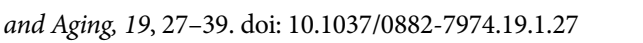

Higgins, J. P. T., \& Green, S. (2011) Cochrane handbook for systematic reviews of interventions. Version 5.1.0. The Cochrane Collaboration.

${ }^{\star}$ Horn, S. S., Bayen, U. J., Smith, R. E., \& Boywitt, C. D. (2011). The multinomial model of prospective memory: Validity of ongoingtask parameters. Experimental Psychology, 58, 247-255. doi: 10.1027/1618-3169/a000091 الملسلسلة

${ }^{\star}$ Khan, A., Sharma, N. K., \& Dixit, S. (2008). Cognitive load and task condition in event- and time-based prospective memory: An experimental investigation. The Journal of Psychology, 142, 517-531. doi: 10.3200/JRLP.142.5.517-532 السلسلس

${ }^{\star}$ Kidder, D. P., Park, D. C., Hertzog, C., \& Morrell, R. W. (1997). Prospective memory and aging: The effects of working memory and prospective memory task load. Aging, Neuropsychology, and

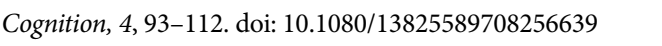

Kliegel, M., Martin, M., McDaniel, M., \& Einstein, G. (2002). Complex prospective memory and executive control of working memory: A process model. Psychologische Beitrage, 44, 303-318. Iلسلسلس

Kliegel, M., Ramuschkat, G., \& Martin, M. (2003). Executive functions and prospective memory performance in old age: An analysis of eventbased and time-based prospective memory. Archives of Gerontology and Geriatrics, 36, 35-41. doi: 10.1007/s00391-003-0081-5 البلسلس

${ }^{\star}$ Lee, J., \& McDaniel, M. A. (2013). Discrepancy-plus-search processes in prospective memory retrieval. Memory amd Cognition, 41, 443- 
451. doi: 10.3758/s13421-012-0273-6

${ }^{\star}$ Lewis-Peacock, J. A., Cohen, J. D., \& Norman, K. A. (2016). Neural evidence of the strategic choice between working memory and episodic memory in prospective remembering. Neuropsychologia, 93A, 280-288. doi: 10.1016/j.neuropsychologia.2016.11.006 لس

Loftus, E. F. (1971). Memory for intentions: The effect of presence of a cue and interpolated activity. Psychological Science, 23, 315-316. doi: 10.3758/BF03336128 سلس

${ }^{\star}$ Logie, R. H., Maylor, E. A., Della Sala, S., \& Smith, G. (2004). Working memory in event- and time-based prospective memory tasks: Effects of secondary demand and age. European Journal of Cognitive Psychology, 16, 441-456. doi: 10.1080/09541440340000114 المالسلسلة

${ }^{*}$ Marsh, R. L., Hancock, T. W., \& Hicks, J. L. (2002). The demands of an ongoing activity influence the success of event-based prospective memory. Psychonomic Bulletin and Review, 9, 604-610. doi: 10.3758/BF03196319 سلس

${ }^{\star}$ Marsh, R. L., \& Hicks, J. L. (1998). Event-based prospective memory and executive control of working memory. Journal of Experimental Psychology: Learning, Memory, and Cognition, 24, 336-349. doi: 10.1037/0278-7393.24.2.336 السلسلس

Marsh, R. L., Hicks, J. L., \& Hancock, T. W. (2000). On the interaction of ongoing cognitive activity and the nature of an event-based intention. Applied Cognitive Psychology, 14, S29-S41. doi: 10.1002/acp.769 لس

${ }^{\star}$ Martin, M., \& Schumann-Hengsteler, R. (2001). How task demands influence time-based prospective memory performance in young and older adults. International Journal of Behavioral Development, 25, 386-391. doi: 10.1080/01650250042000302 المالسلس

${ }^{\star}$ Matos, P., Santos, F. H., \& Albuquerque, P. B. (2020). When we must forget: The role of cognitive load on prospective memory commission errors. Memory, 28, 374-385. doi: 10.1080/09658211.2020.1726399 الس السلس McDaniel, M. A., \& Einstein, G. O. (2000). Strategic and automatic processes in prospective memory retrieval: A multiprocess framework. Applied Cognitive Psychology, 14, S127-S144. doi: 10.1002/acp.775 الس السلسل McDaniel, M. A., \& Einstein, G. O. (2007). Spontaneous retrieval in prospective memory. In J. S. Nairne (Ed.), The foundations of remembering: Essays in honor of Henry L. Roediger, III (pp. 225-240). Psychology Press.

${ }^{*}$ McDaniel, M. A., Guynn, M. J., Einstein, G. O., \& Breneiser, J. (2004). Cue-focused and reflexive-associative processes in prospective memory retrieval. Journal of Experimental Psychology: Learning, Memory, and Cognition, 30, 605-614. doi: 10.1037/02787393.30.3.605 الس الس

${ }^{\star}$ McDaniel, M. A., Howard D. C., \& Butler, K. M. (2008). Implementation intentions facilitate prospective memory under high attention demands. Memory and Cognition, 36, 716-724. doi: 10.3758/MC.36.4.716 الفلسلسلس

${ }^{*}$ McDaniel, M. A., Robinson-Riegler, B., \& Einstein, G. O. (1998). Prospective remembering: Perceptually driven or conceptually driven processes? Memory and Cognition, 26, 121-134. doi: 10.3758/ BF03211375 السلسلس

${ }^{\star}$ McDaniel, M. A., \& Scullin, M. K. (2010). Implementation intention encoding does not automatize prospective memory responding.
Memory and Cognition, 38, 221-232. doi: 10.3758/MC.38.2.221 إلسلس ${ }^{\star}$ McGann, D., Ellis, J. A., \& Milne, A. (2002). Conceptual and perceptual processes in prospective remembering: Differential influence of attentional resources. Memory and Cognition, 30, 1021-1032. doi: 10.3758/BF03194320 س山س

${ }^{*}$ McNerney, M. W., \& West, R. (2007). An imperfect relationship between prospective memory and the prospective interference effect. Memory and Cognition, 35, 275-282. doi: 10.3758/BF03193448 المالسلسل Meier, B., \& Zimmermann, T. D. (2015). Loads and loads and loads: The influence of prospective load, retrospective load, and ongoing task load in prospective memory. Frontiers in Human Neuroscience, 9, 322. doi: 10.3389/fnhum.2015.00322 الس السلس

Moher, D., Shamseer, L., Clarke, M., Ghersi, D., Liberati, A., Petticrew, M., Shekelle, P., A Stewart, L. A., \& PRISMA-P Group (2015). Preferred reporting items for systematic review and meta-analysis protocols (PRISMA-P) 2015 statement. Systematic Reviews, 6, e1000097. doi: 10.1371/journal.pmed1000097 السلسلس

Monsell, S. (2003). Task-switching. Trends in Cognitive Sciences, 7 , 134-140. doi: 10.1016/S1364-6613(03)00028-7 المالسلس

${ }^{\star}$ Möschl, M., Walser, M., Surrey, C., \& Miller, R. (2019). Prospective memory under acute stress: The role of (output) monitoring and ongoing-task demands. Neurobiology of Learning and Memory, 164, e107046. doi: 10.1016/j.nlm.2019.107046 المالسلس

${ }^{\star}$ Otani, H., Landau, J. D., Libkuman, T. M., Louis, J. P. St., Kazen, J. K., \& Throne, G. W. (1997). Prospective memory and divided attention. Memory, 5, 343-360. doi: 10.1080/741941393 المالسلسلة

*Pereira, D. R., Albuquerque, P. B., \& Santos, F. H. (2018). Event-based prospective remembering in task-switching conditions: Exploring the effects of immediate and postponed responses in cue detection. Australian Journal of Psychology, 70, 149-157. doi: 10.1111/ajpy.12174 السلسلس

${ }^{\star}$ Pink, J. E., \& Dodson, C. S. (2013). Negative prospective memory: Remembering not to perform an action. Psychonomic Bulletin and Review, 20, 184-190. doi: 10.3758/s13423-012-0337-4 المالسلسل

${ }^{\star}$ Rendell, P. G., McDaniel, M. A., Forbes, R. D., \& Einstein, G. O. (2007). Age-related effects in prospective memory are modulated by ongoing task complexity and relation to target cue. Aging, Neuropsychology, and Cognition, 14, 236-256. doi: 10.1080/13825580600579186 المالسلس

Rose, N., Rendell, P. G., McDaniel, M. A., Aberle, I., \& Kliegel, M. (2010). Age and individual differences in prospective memory during a "virtual week": The roles of working memory, vigilance, cue focality, and task habituation. Psychology and Aging, 25, 595-605. doi: 10.1037/a0019771 الس الس

Rugg, M. D., \& Vilberg, K. L. (2013). Brain networks underlying episodic memory retrieval. Current Opinion in Neurobiology, 23, 255-260. doi: 10.1016/j.conb.2012.11.005 سلس

${ }^{\star}$ Rummel, J., Wesslein, A., Meiser, T. (2016). The role of action coordination for prospective memory: Task-interruption demands affect intention realization. Journal of Experimental Psychology: Learning, Memory, and Cognition, 43, 717-735. doi: 10.1037/xlm0000334 السلسلسال

Rusted, J. M. \& Trawley, S. (2006). Comparable effects of nicotine in smokers and non-smokers on a prospective memory task. Neuropsychopharmacology, 31, 1545-1549. doi: 10.1038/ 


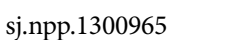

Schaper, P., \& Grundgeiger, T. (2019). Commission errors with forced response lag. The Quarterly Journal of Experimental Psychology, 72(, 2380-2392. doi: 10.1177/1747021819840583 سلس

Schnitzspahn, K. M., Stahl, C., Zeintl, M., Kaller, C. P., \& Kliegel, M. (2013). The role of shifting, updating, and inhibition in prospective memory performance in young and older adults. Developmental Psychology, 49, 1544-1553. doi: 10.1037/a0030579 الس السلس

Scullin, M. K., \& Bugg, J. M. (2013). Failing to forget: Prospective memory commission errors can result from spontaneous retrieval and impaired executive control. Journal of Experimental Psychology: Learning, Memory, and Cognition, 39, 965-971. doi: 10.1037/a0029198 الس الس الس

Scullin, M. K., Bugg, J. M., \& McDaniel, M. A. (2012). Whoops, I did it again: Commission errors in prospective memory. Psychology and Aging, 27, 46-53. doi: 10.1037/a0026112 الف السلبل

Scullin, M. K., McDaniel, M. A, \& Einstein, G. O. (2010). Control of cost in prospective memory: Evidence for spontaneous retrieval processes. Journal of Experimental Psychology: Learning, Memory, and Cognition, 36, 190-203. doi: 10.1037/a0017732 الس الس الس

Shelton, J. T., \& Scullin, M. K. (2017). The dynamic interplay between bottom-up and top-down processes supporting prospective remembering. Current Directions in Psychological Science, 26, 352-358. doi:

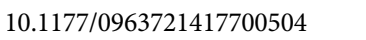

Shum, D., Cahill, A., Hohaus, L. C., O'Gorman, J. G., \& Chan, R. C. K. (2013). Effects of aging, planning, and interruption on complex prospective memory. Neuropsychological Rehabilitation, 23, 1-19. doi: 10.1080/09602011.2012.716761 السالسلس

Smith, R. E. (2003). The cost of remembering to remember in eventbased prospective memory: Investigating the capacity demands of delayed intention performance. Journal of Experimental Psychology: Learning, Memory, and Cognition, 29, 347-361. doi: 10.1037/0278-

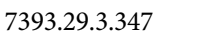

Smith, R. E., \& Bayen, U. J. (2005). The effects of working memory resource availability on prospective memory: A formal modeling approach. Experimental Psychology, 52, 243-256. doi: 10.1027/16183169.52.4.243 |لس

${ }^{*}$ Smith, R. E., Horn, S. S., \& Bayen, U. J. (2012). Prospective memory in young and older adults: The effects of ongoing-task load. Aging, Neuropsychology, and Cognition, 19, 495-514. doi: 10.1080/13825585.2011.633161 البلس

${ }^{*}$ Smith, R. E., \& Hunt, R. R. (2014). Prospective memory in young and older adults: The effects of task importance and ongoing task load. Aging, Neuropsychology, and Cognition, 21, 411-431. doi: 10.1080/13825585.2013.827150 الس

*Stone, M., Dismukes, K., \& Remington, R. (2001). Prospective memory in dynamic environments: Effects of load, delay, and phonological rehearsal. Memory, 9, 165-176. doi: 10.1080/09658210143000100 الس السلسل| Trawley, S. L., Law, A. S., Brown, L. A., Niven, E. H., \& Logie, R. H. (2014). Prospective memory in a virtual environment: Beneficial effects of cue saliency. Journal of Cognitive Psychology, 26, 39-47. https://doi.org/10.1080/20445911.2013 سلس الس

Uttl, B. (2011). Transparent meta-analysis: Does aging spare prospective memory with focal vs. non-focal cues? PloS One, 6, e16618. doi:

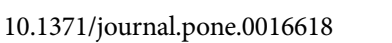

*van Den Berg, S. M., Aarts, H., Midden, C., \& Verplanken, B. (2004). The role of executive processes in prospective memory tasks. European Journal of Cognitive Psychology, 16, 511-533. doi: 10.1080/095414400340000240 السلسلس

*West, R., \& Bowry, R. (2005). Effects of aging and working memory demands on prospective memory. Psychophysiology, 42, 698-712. doi: 10.1111/j.1469-8986.2005.00361.x الس الس

${ }^{*}$ West, R., Bowry, R., \& Krompinger, J. (2006). The effects of working memory demands on the neural correlates of prospective memory. Neuropsychologia, 44, 197-207. doi: 10.1016/j.neuropsychologia.2005.05.003 السلسلسل

*West, R., Scolaro, A. J., \& Bailey, K. (2011). When goals collide: The interaction between prospective memory and task-switching. Canadian Journal of Experimental Psychology, 65, 38-47. doi: 10.1037/a0022810 الس الس

Zimmermann, T. D., \& Meier, B. (2006). The rise and decline of prospective memory across the lifespan. The Quarterly Journal of Experimental Psychology, 59, 2040-2046. doi: 10.1080/17470210600917835 سلس

Zollig, J., West, R., Martin, M., Altgassen, M., Lemke, U., \& Kliegel, M. (2007). Neural correlates of prospective memory across the lifespan. Neuropsychologia, 45(14), 3299-3314. doi: 10.1016/j.neuropsychologia.2007.06.010 السلسلس

Zuber, S., \& Kliegel, M. (2019). Prospective memory development across the lifespan: An integrative framework. European Psychologist, 25, 162-173. 


\section{SUPPLEMENTARY MATERIALS}

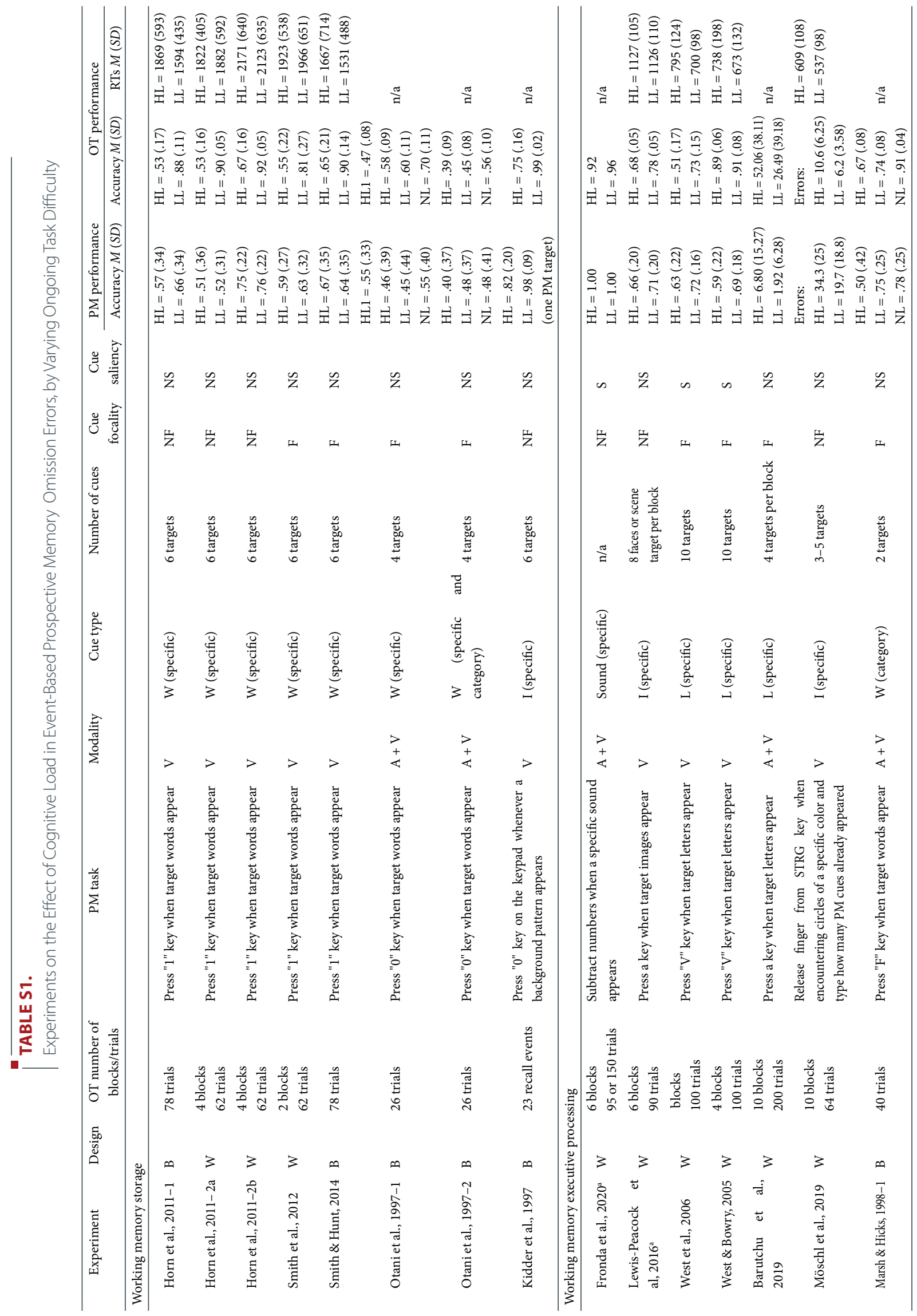




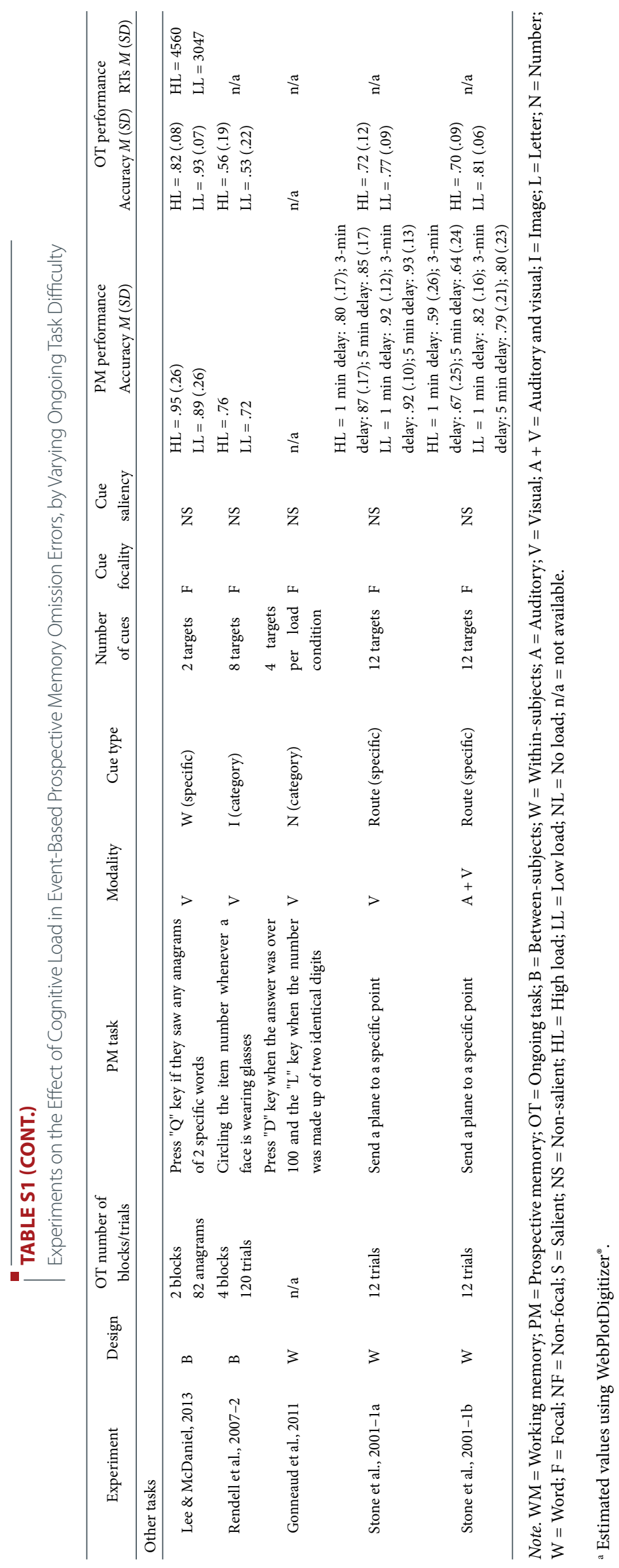




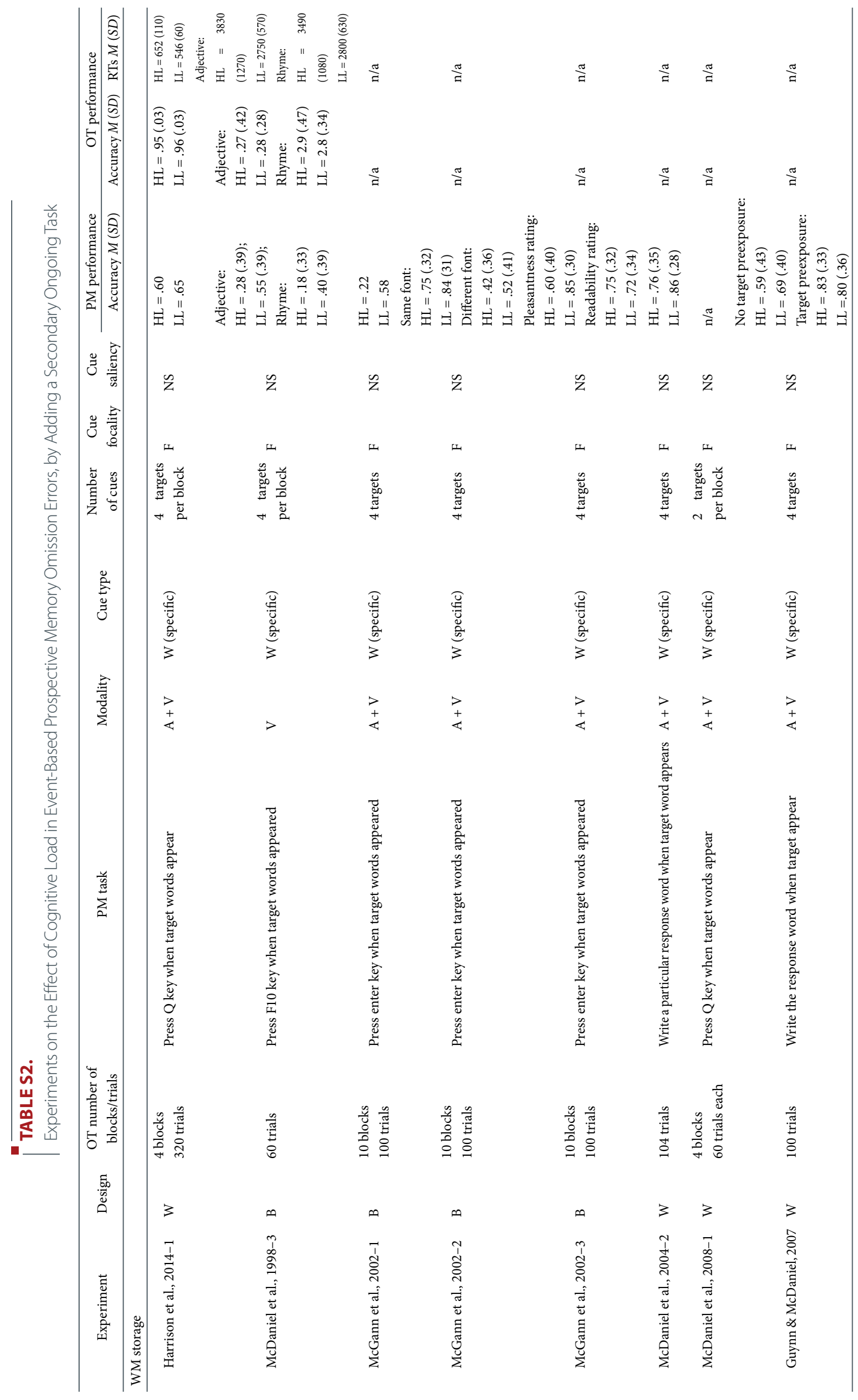




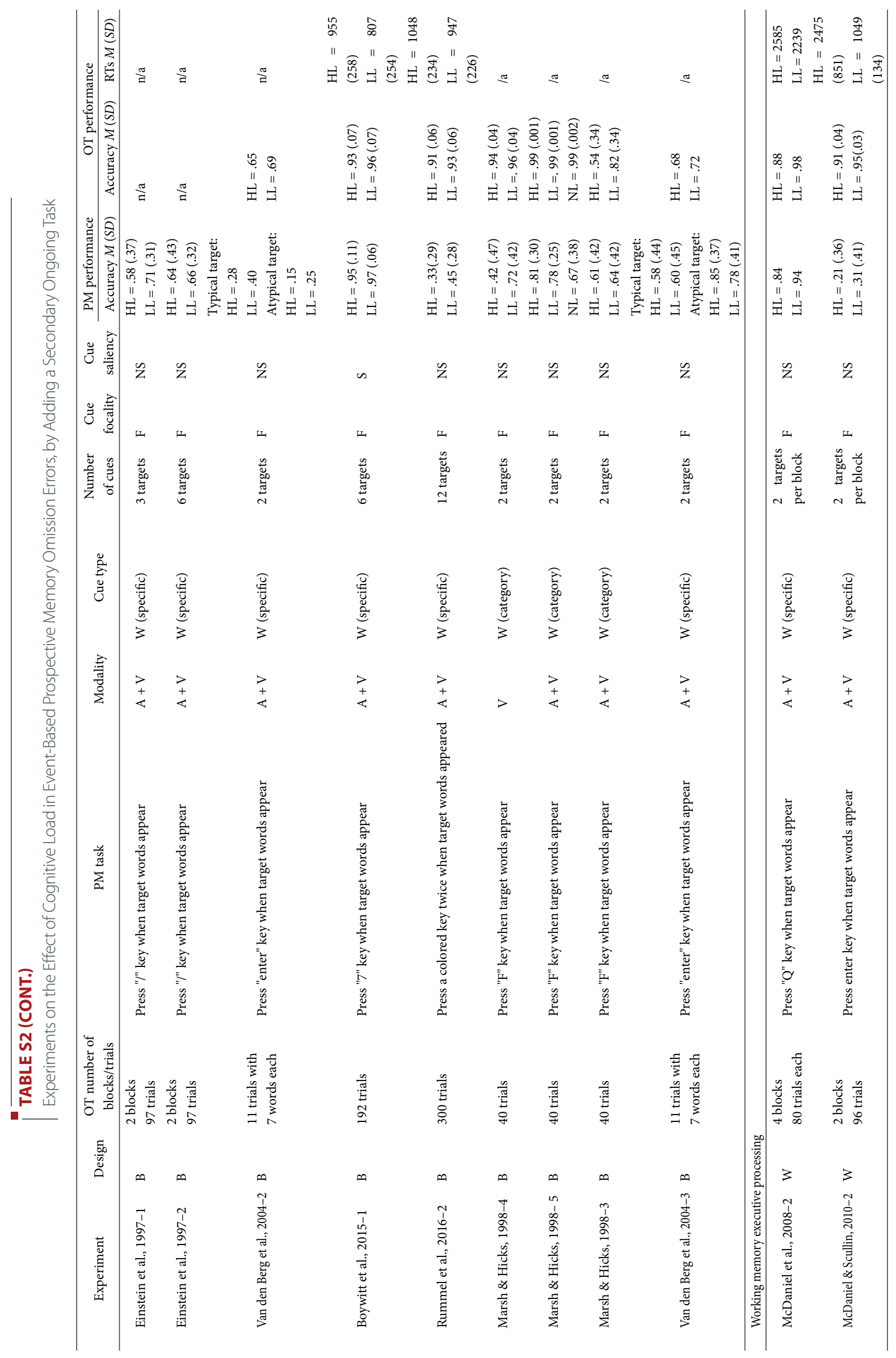




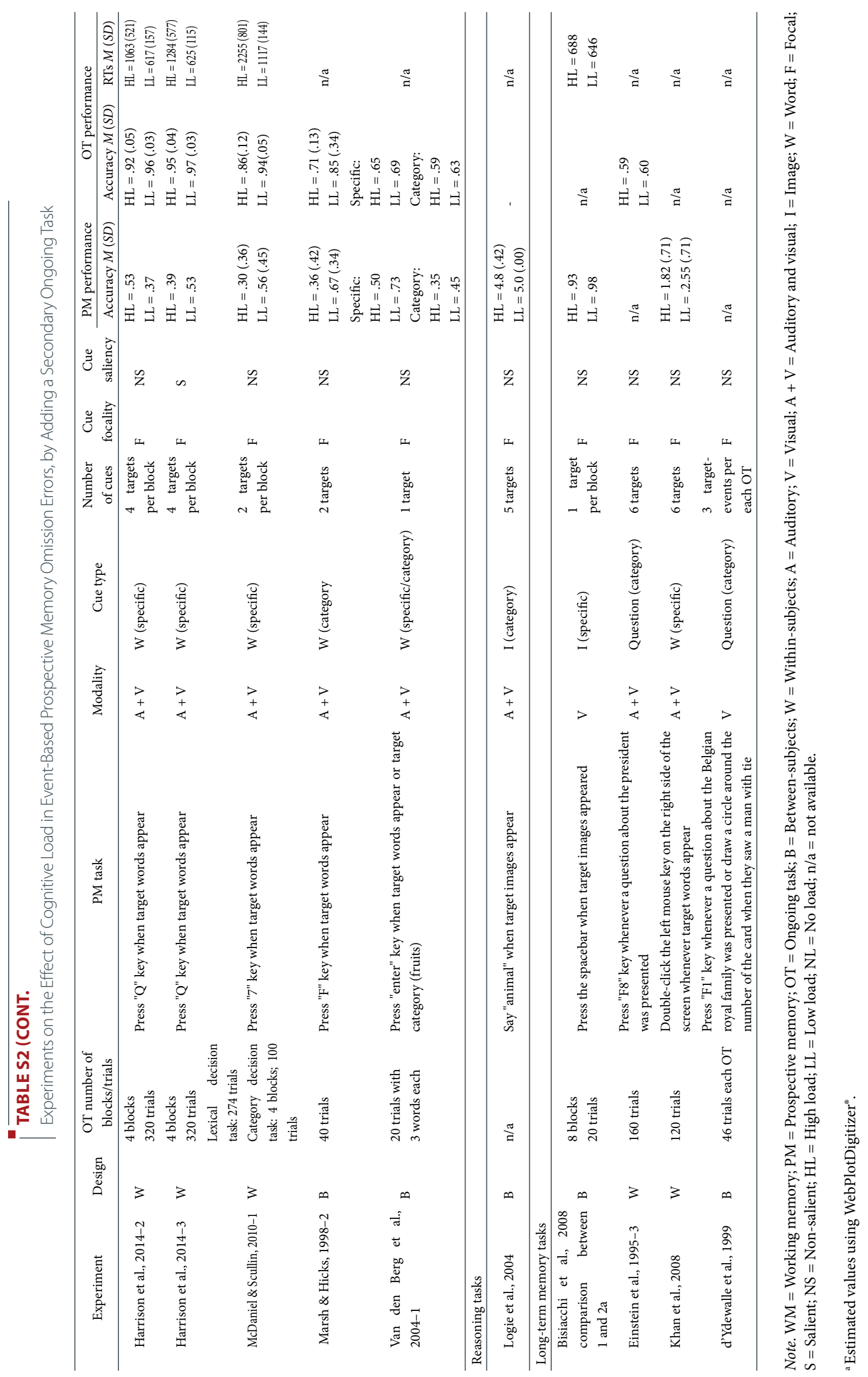




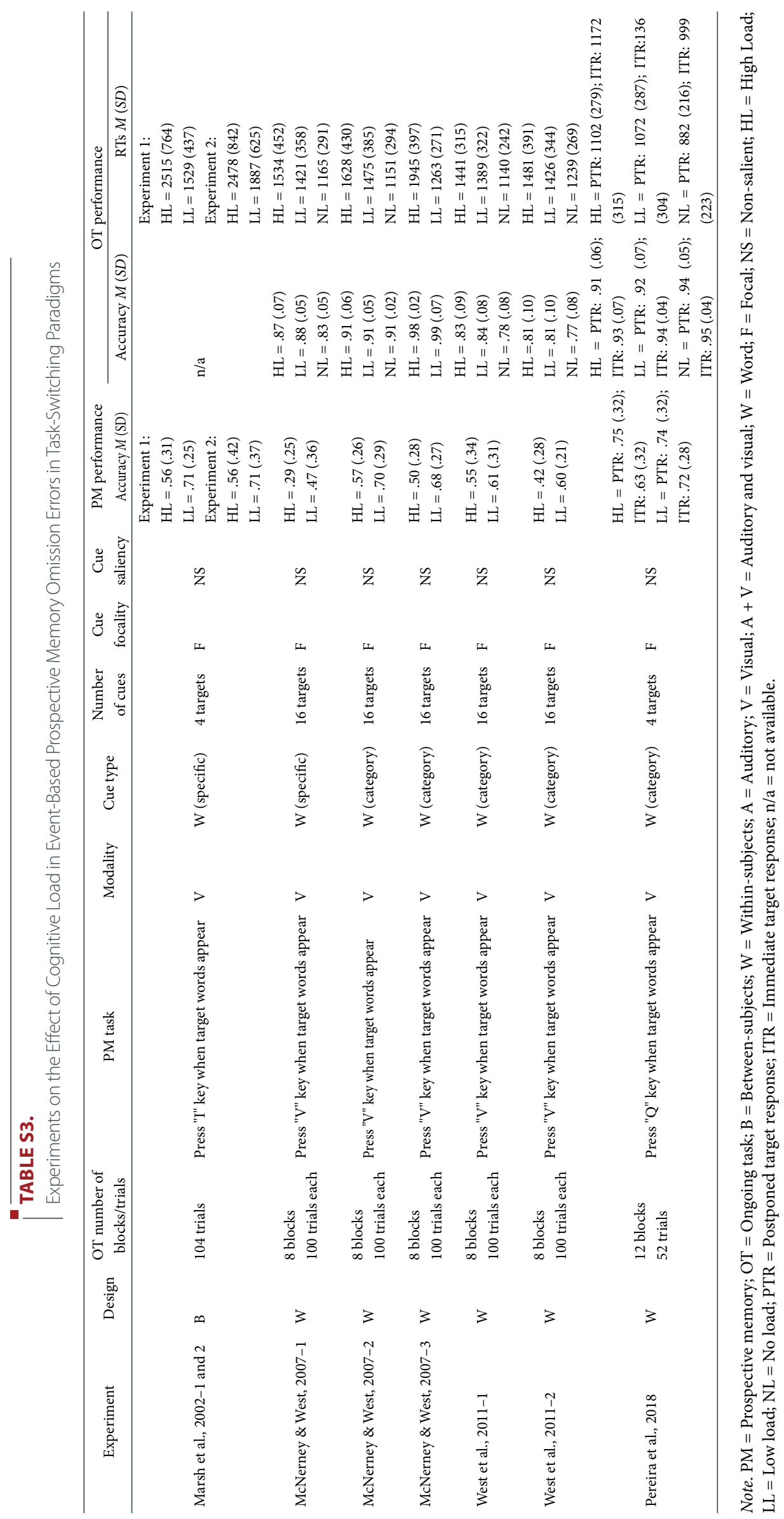




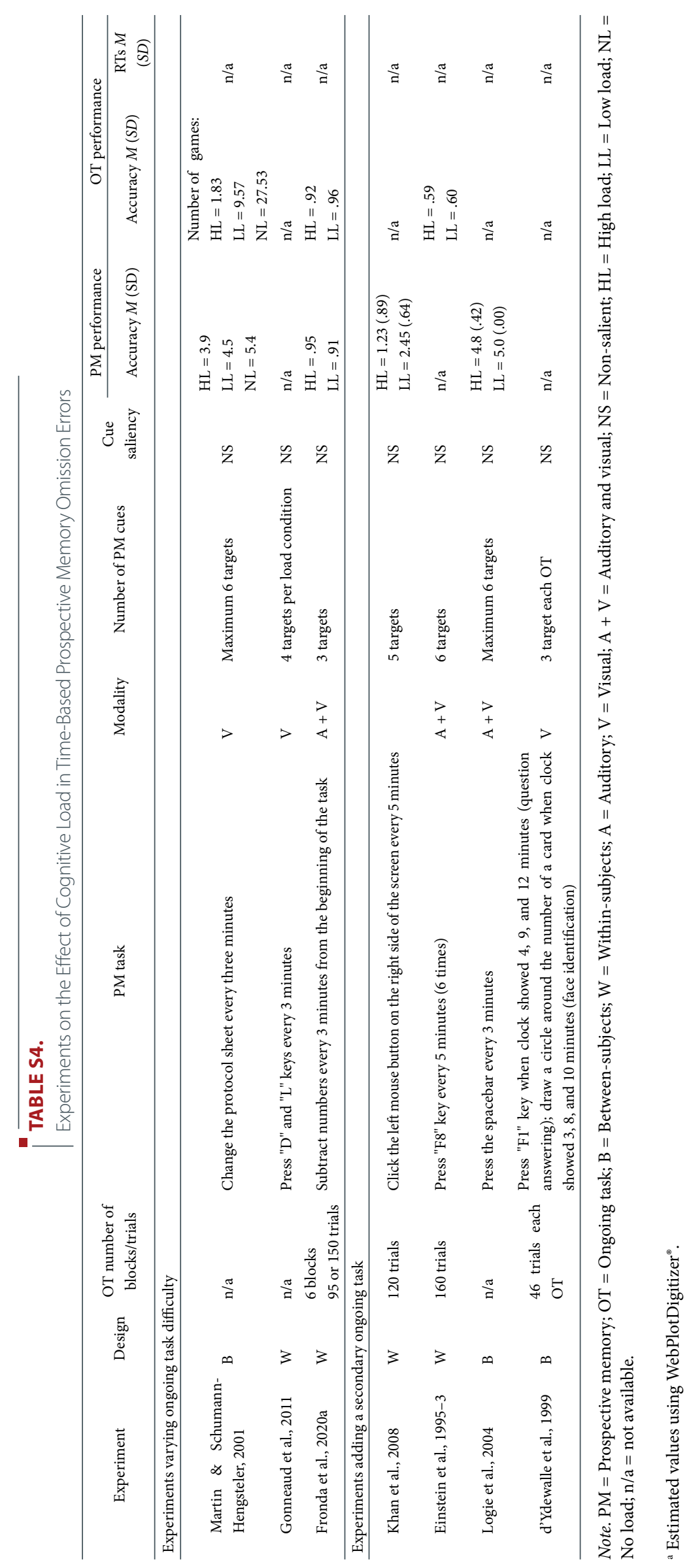




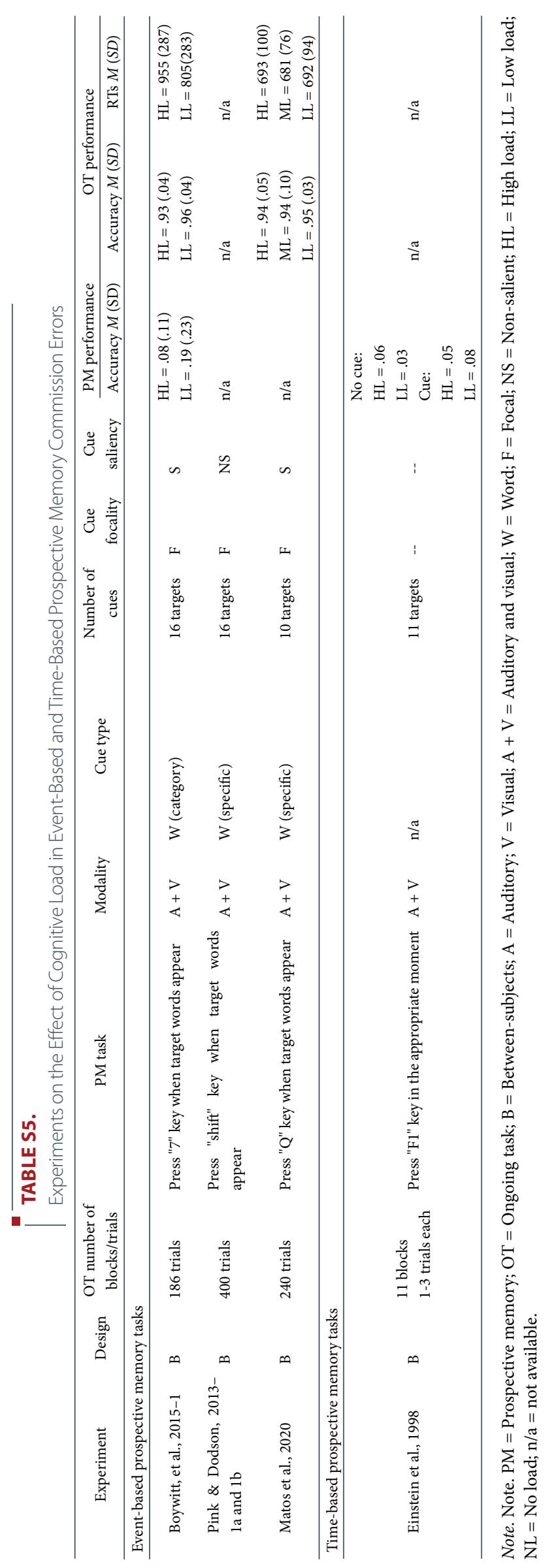

